\title{
The Role of Ettringite in the Deterioration of Artificial Lime Stabilised Soils: A Microstructural Study
}

\begin{abstract}
The formation of ettringite has been defined as a major failure mechanism of lime stabilised cohesive soils. It can result in both disruptive volumetric changes and loss of mechanical strength. The mechanisms of its formation and the role it plays in deleterious processes are complex. This paper reports the dimensional and strength changes of a range of artificial lime stabilised cohesive soils subject to two swell test procedures: the UK linear CBR swell test (BS1924-2, BSI 1990) and the European accelerated swell test (EN13286-49, CEN 2007). The resulting microstructural composition was analysed using a combination of Scanning Electron Microscopy and Electron Dispersive X-ray Spectroscopy (SEM-EDX). The results are explained in terms of established theories of crystal formation and subsequent expansion mechanisms.
\end{abstract}

KEYWORDS: Swell Test, Lime, Soil, Ettringite, SEM, EDX

Road Materials and Pavements Design. Volume X - No X/2010, pages 1 to $\mathrm{n}$ 


\section{Introduction}

Soil stabilisation can be defined as the enhancement of the engineering properties of a soil by blending in a chemical or granular additive [McNally, 1998]. Engineering properties improved by the application of soil stabilisation techniques include increases in stiffness; strength and durability. Soil stabilisation allows insitu material to be used as either a temporary or permanent structure in engineering works. Applications include: pavement foundations (capping and subbase); temporary working platforms; sea defences and slope stabilisation.

Under UK specifications (Specifications for Highway Works, Highways Agency., 2009), if a pavement foundation is to be constructed on a weak subgrade $(\mathrm{CBR}<5 \%)$, a stabilised capping layer (with improved engineering performance) can be constructed, so that sufficient support is provided to the overlaying pavement. This incorporates the insitu material into the final works and also allows a reduction in the thickness of the overlaying layers [McNally, 1998]. Economic and environmental benefits are realised through a reduction in primary material use; fewer lorry movements; avoidance of landfill tax (associated with the disposal of excavated material) and reductions in embodied energies [Britpave, Case Studies 1 - 10, 2010 - 2011].

However, under certain conditions stabilised soils can exhibit the phenomenon of what is often termed sulfate heave. This results from deleterious reactions that occur within the stabilised layer, resulting in disruptive volumetric changes and corresponding losses in strength. A number of often cited pavement failures [Mitchell, 1986; Hunter, 1988; Snedker and Temporal, 1990; Perrin, 1992; Kota et al., 1996; Puppala, 1999; Rollings et al., 1999 and Cerato and Miller, 2011] have been attributed to this deleterious mechanism. Risk mitigation measures in the UK use a combination of prescriptive material suitability requirements, in combination with laboratory test methods that aim to evaluate a soils response to stabilisation, under controlled conditions, that reflect those found insitu.

This paper reports the use of two such laboratory tests to evaluate the physical response (in terms of dimensional stability and strength) of a range of what would be considered to be 'problematic or unsuitable' artificial soils, in relationship to their underlying microstructural and chemical changes. The ultimate aim of which, is to further the understanding of such deleterious processes. 


\section{Background}

The use of lime either as calcium oxide $(\mathrm{CaO})$ known as quicklime, or calcium hydroxide $\left(\mathrm{Ca}(\mathrm{OH})_{2}\right)$, known as slaked lime, is classified as chemical stabilisation. There can be considered two distinct phases of soil stabilisation using lime. The first is modification and the second stabilisation. Modification in this context refers to the initial alteration of particular soil properties. Namely a reduction in water content (more so when $\mathrm{CaO}$ is used over $\mathrm{Ca}(\mathrm{OH})_{2}$ ), plasticity and density. These are the result of the drying effect of the lime and of cation exchange processes that reduce interparticle repulsion, causing the clay particles to flocculate together [Sherwood, 1962]. This in itself improves the workability of the soil and is particularly marked for 'heavy clays' such as London and Gault clay (West et al, 1997)..

Following the initial modification, the soil then undergoes stabilisation. This is associated with the development of a cementitious matrix that forms within the soil and binds it together and leads to a reduction in free swell potential and increases in bearing capacity. Stabilisation occurs when a sufficient quantity of stabiliser has been added to the soil and is measured using the Eades and Grim test (Eades and Grim, 1966). It is referred to in the UK as the Initial Consumption of Lime (ICL) value and is defined as the amount of lime required to raise the $\mathrm{pH}$ of the soil to 12.4. Under this highly alkaline environment, the aluminosilicate sheets that constitute the clay particles become soluble at $\mathrm{pH}>10.4$ with optimum solubility being achieved at pH 12.4 [Bell, 1996], The disassociation of clay minerals under alkaline conditions is shown in (Eq. 1):

(Eq. 1) $\mathrm{Al}_{2} \mathrm{Si}_{4} \mathrm{O}_{10}(\mathrm{OH})_{2} \cdot \mathrm{nH}_{2} \mathrm{O}+2(\mathrm{OH})^{-}+10 \mathrm{H}_{2} \mathrm{O} \rightarrow 2\left\{2 \mathrm{Al}(\mathrm{OH})_{4}{ }^{-}+4 \mathrm{H}_{4} \mathrm{SiO}_{4}\right\}+$ $\mathrm{nH}_{2} \mathrm{O}$

This then enables the dissolved clay particles to react with free calcium ions in solution to form calcium silicate hydrates $(\mathrm{CSH})$, calcium aluminate hydrates $(\mathrm{CAH})$ and calcium aluminium silicate hydrates (CASH), usually described using generic formulas. These are groups of cementitious products that may be final products or meta-stable intermediates, the co-dependent reactivity of which, contributes to the complexity and difficulty in the study of cementitious systems. For example, the hydrated minerals with cementitious properties: $\mathrm{C}_{4} \mathrm{AH}_{13} ; \mathrm{C}_{3} \mathrm{AH}_{11} ; \mathrm{CAH}_{10} ; \mathrm{C}_{3} \mathrm{~S}_{2} \mathrm{H}_{3}$ and $\mathrm{C}_{2} \mathrm{ASH}_{8}$ have all been identified in stabilised soils [Bell, 1996].

These cementitious products are equivalent to those formed during the hydration of cement pastes. The insoluble hydrates form a cementitious matrix which fills void spaces within the soil to encompass unreacted clay particles. Subsequent curing of this cementitious matrix results in material with increased engineering performance. This is illustrated in Figure 1: 


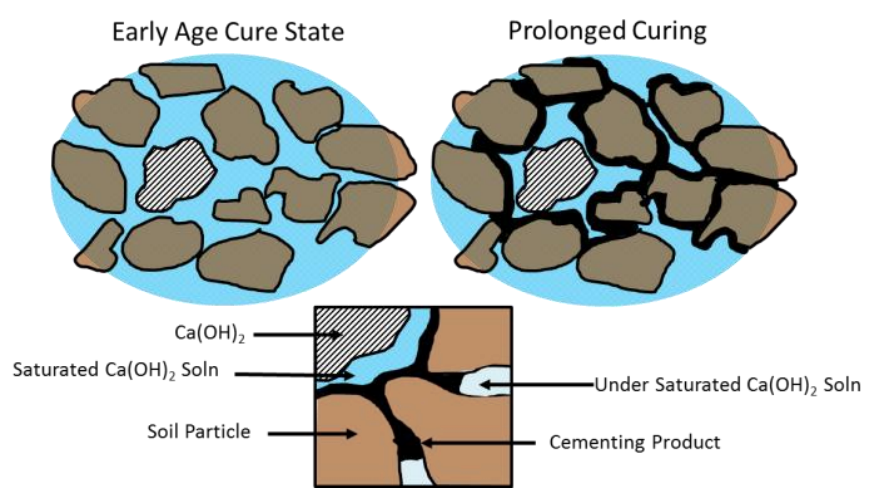

Figure 1. The development of a cementitious matrix in lime stabilised clay soil [adapted from Locat el al., 1990].

So long as the soil remains alkali $(\mathrm{pH}>10.4)$ the dissolution of clay minerals and subsequent pozzolanic reactions will continue. The strength of the soil will then also continue to increase with time for months or even years after mixing. The ultimate effect of lime stabilisation is dependent on the soil composition; lime content; clay mineralogy; curing temperature and soil $\mathrm{pH}$ [Mohamed, 2000].

Sulfate heave occurs when sulfate minerals already present in the soil (or transported there by mobile ground water), react with the lime and/or cement used in the stabilisation along with alumina from dissolved clay particles to form expansive minerals called Ettringite, Monosulfate and Thaumasite. When these minerals form after the stabilised layer has been mixed and compacted, they exert pressure on the soil because they have a greater unit volume, than the reactants they were derived from [Little, 2010]. This results in sulfate heave and causes significant damage to the entire pavement structure. This can manifest itself as both transverse and longitudal ridges and cracks in the pavement surface, as well as discreet areas where the strength loss in the foundation is so severe that significant permanent deformation can occur [Hunter, 1988; Snedker and Temporal, 1990 and Rollings et al., 1999]. As previously described, the addition of lime to a soil containing clay minerals increases the $\mathrm{pH}$ to $>10.5$ (Eq. 2) prompting the dissolution of aluminosilicates into the pore solution (Eq. 3):

(Eq. 2) $\mathrm{Ca}(\mathrm{OH})_{2} \rightarrow \mathrm{Ca}^{2+}+2(\mathrm{OH})^{-}$

(Eq. 3) $\mathrm{Al}_{2} \mathrm{Si}_{4} \mathrm{O}_{10}(\mathrm{OH})_{2} \cdot \mathrm{nH}_{2} \mathrm{O}+2(\mathrm{OH})^{-}+10 \mathrm{H}_{2} \mathrm{O} \rightarrow 2\left\{2 \mathrm{Al}(\mathrm{OH})_{4}{ }^{-}+4 \mathrm{H}_{4} \mathrm{SiO}_{4}\right\}+\mathrm{nH}_{2} \mathrm{O}$

The aluminate ions $-\mathrm{Al}(\mathrm{OH})_{4}{ }^{-}$react with sulfate ions from the dissolution of gypsum (Eq. 4) to form ettringite (in this case the trisulfate form) shown in (Eq. 5):

(Eq. 4) $\mathrm{CaSO}_{4} \cdot 2 \mathrm{H}_{2} \mathrm{O} \rightarrow 2 \mathrm{Ca}^{2+}+\mathrm{SO}_{4}{ }^{2-}+2 \mathrm{H}_{2} \mathrm{O}$

(Eq. 5) $6 \mathrm{Ca}^{2+}+2 \mathrm{Al}(\mathrm{OH})_{4}{ }^{-}+4 \mathrm{OH}^{-}+3 \mathrm{SO}_{4}{ }^{2-}+26 \mathrm{H}_{2} \mathrm{O} \rightarrow \mathrm{Ca}_{6}\left[\mathrm{Al}(\mathrm{OH})_{6}\right]_{2} \cdot\left(\mathrm{SO}_{4}\right)_{3} \cdot 26 \mathrm{H}_{2} \mathrm{O}$

Therefore the anionic sulfate $\left(\mathrm{SO}_{4}{ }^{2-}\right)$, alumina $\left(\mathrm{Al}(\mathrm{OH})_{4}{ }^{-}\right)$and cationic calcium $\left(\mathrm{Ca}^{2+}\right)$ ions can be considered the candidate ions [Puppala, 2005 and Little et al., 2010] for the formation of ettringite in cohesive soil and must be present for it to 
occur. The formation of ettringite during lime stabilisation of cohesive soils is shown in Figure 2.

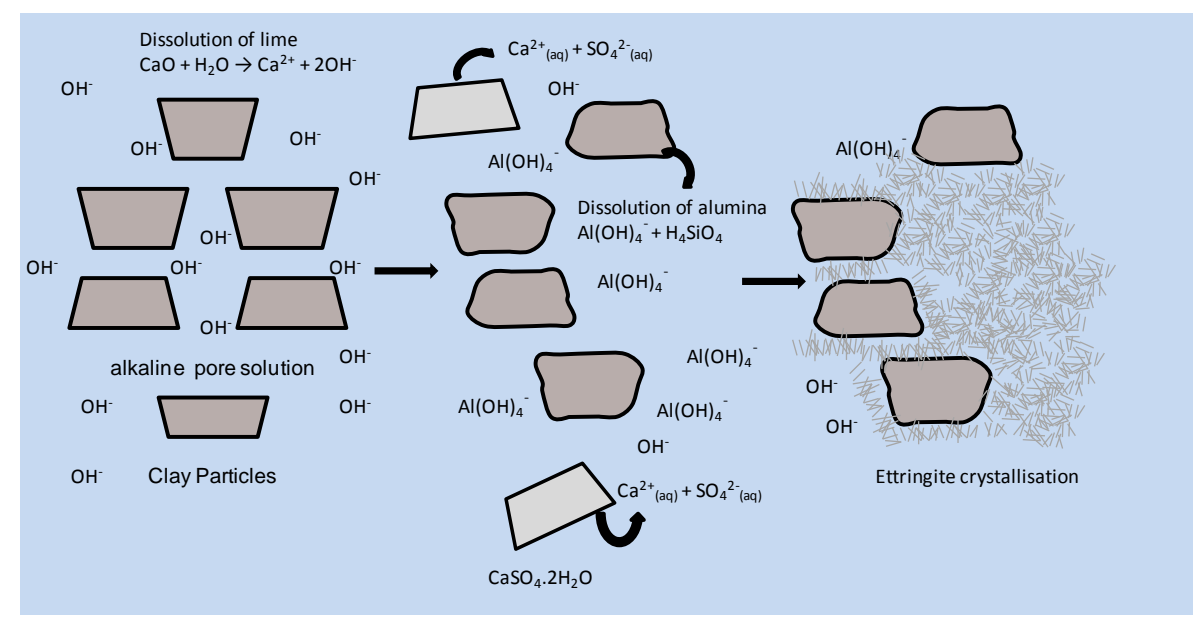

Figure 2. Diagram depicting ettringite (AFt) formation in lime stabilised cohesive soils.

With regard to the mechanism by which ettringite can form, Basista and Weglewski (2009) summarised early work described in the literature that derived two competing theories:

- $\quad$ the 'topochemical' mechanism [Kalousek and Benton, 1970; Mather, 1973; Soroka, 1980; Ogawa and Roy, 1981; Cohen, 1983; Odler and Gasser, 1988; Brown and Taylor, 1999]; and

- the 'through-solution' mechanism [Mehta, 1973; Mehta, 1976; Mehta and $\mathrm{Hu}, 1978$; Mehta and Wang, 1982; Ogawa and Roy, 1982; Odler and Glasser, 1988; Ping and Beaudoin, 1992; Min and Tang, 1993].

In the topochemical mechanism, crystal growth occurs at the solid-solution interface. This can occur when the rate of ettringite crystallisation is greater than the dissolution rate of the candidate ions. Considering the almost instantaneous hydration of the cement clinker phase of tricalcium aluminate $-\mathrm{C}_{3} \mathrm{~A}$, by the topochemical mechanism [Kirchheim et al., 2009], the dissolving aluminate ions $\mathrm{Al}(\mathrm{OH})_{4}{ }^{-}$cannot migrate far into the pore solution, because the supersaturation of the liquid phase with respect to ettringite is so low. By this mechanism, damage occurs when the regions of crystal growth intersect and mutually exert pressure, forcing the particles apart [Cohen, 1983].

In the through-solution model, on hydration, the solid particles begin to dissolve and their corresponding ions move into aqueous solution. When the pore solution becomes supersaturated with respect to ettringite, then ettringite crystallises out. In this manner, it can form away from the source of alumina, generally in the bulk pore solution and is characterised by nucleation and crystal growth at many sites, 
frequently in void spaces throughout the material [Min and Tang, 1993]. Because of this ability to migrate through the pore solution and crystallise in parts of the material which can accommodate crystal growth, the occurrence of ettringite in this case is not considered deleterious. No damage to the cementitious matrix may necessarily occur, due to the air-entrainment void space being able to accommodate the crystal growth. As such, the through-solution mechanism is considered less deleterious than formation by the topochemical mechanism [Kalousek and Benton, 1970 and Soroka, 1979].

Early work on damage mechanisms of cementitious materials resulted in two competing theories being proposed:

- the 'crystal growth' theory [Nakamura, 1960; Schwiete, 1966; Kalousek and Benton, 1970; Ish-Shalom and Bentur, 1974; Ogawa and Roy, 1982;]; and

- the 'crystal swelling' theory [Mehta, 1973, 1976; Chen and Mehta, 1982; Min and Tang, 1993].

In the crystal growth theory, expansion occurs when reaction zones of ettringite formation intersect, continue growing and mutually exert pressure, this can result from crystals growing on the surface of other particles (topochemically) or in the pore solution (through-solution).

In the crystal swelling theory, expansion is caused by the swelling of relatively small ettringite crystals that are colloidal or gel size. Expansive stress results from the conversion of free energy of the reaction to work [Kalousek and Benton, 1970].

Ogawa and Roy (1982) observed the formation of ettringite on the surface of $\mathrm{C}_{4} \mathrm{~A}_{3}$ particles. These grew raidially out into the pore solution. Expansion began when these reaction zones intersected and mutually exerted pressure. Schwiete et al. (1966) studied the $\mathrm{CaO}-\mathrm{Al}_{2} \mathrm{O}_{3}-\mathrm{CaSO}_{4}-\mathrm{CaO}-\mathrm{H}_{2} \mathrm{O}$ system. They concluded that the crystallisation pressure was the result of topochemical $\mathrm{AFt}$ formation on the surface of $\mathrm{C}_{3} \mathrm{~A}$ particles. Because the $\mathrm{AFt}$ crystals occupy a bigger volume than the $\mathrm{C}_{3} \mathrm{~A}$ grains, they eventually peel off. It is this on-going process that eventually results in the crystallisation pressure.

Nakamura et al. (1968) in their studies of the C4A3S-CH-CS system found that at high $\left[\mathrm{OH}^{-}\right]$, AFt formation is topochemical and expansion is caused by the intersection of reaction zones resulting from crystal growth. These crystals were comparatively fine. Conversely when the $\left[\mathrm{OH}^{-}\right]$is low, $\mathrm{AFt}$ formed by throughsolution mechanism precipitated large crystals in the pore solution.

In the crystal swelling theory, ettringite forms by the through-solution mechanism. The crystals are very small - gel-like and colloidal in size (Mehta, 1973). The tiny crystals have a high specific surface area with unsatisfied surface charges. They can absorb ions and water molecules to decrease their surface energy, creating an electric double layer around the ettringite crystals in a similar manner that causes the swelling of particular clays (Little et al., 2010). Intersection of these layers produces the crystal swelling pressure (Min and Tang, 1994). Mehta and Hu 
(1978) found that an increase in the amount of absorbed water corresponded to an increase in volumetric expansion. Ouhadi and Young (2008), showed that AFt can swell by the order of $50 \%$ and its fluid retention increase by as much as $400 \%$ in the soils studied in their research. They concluded that it is the crystal swelling mechanism that is responsible for ettringite induced heave.

Mehta (1973) stated that for colloidal ettringite to cause expansion, it must be in contact with outside water. Quoting Ouhadi and Yong (2008) 'the availability and flow of pore water is the single most important factor controlling lime-induced heave. Without an abundance of water AFt cannot form'. And Little et al. (2010) 'the presence of external water is a decisive factor in causing deleterious reactions in stabilised soils.'

The correlation of ettringite formation and expansion of a cementitious material is thought to be extremely difficult. The precipitation of ettringite in the existing pore structure of a material is not thought to contribute to expansion. The inherent variability of soils results in difficulty in charactering and thereby quantifying the degree of expansion. Overall ettringite and monosulfate formation is dependent on many factors. However, the available alumina content and an excess of water are considered critical factors.

\section{Methodology}

Clay that had undergone an industrial manufacturing process was selected for a number of reasons; the typical spatial inhomogeneities of natural soils make studying their behaviour under stabilisation difficult. Organic, sulfide/sulfate and other minor constituents, typical of a natural soil, have been removed in the processed material, so that it is of known composition. This allows the physicochemical properties of a particular soil mixture to be attributed to the imposed mixture composition and/or test condition. Again, if a natural soil were used in the research, other effects such as expansion/relaxation (a risk with consolidated clays), oxidation of pyritic deposits and action of autotrophic bacteria mean that changes in the characteristics of natural clay are likely over time. This would again make control of mixture composition difficult. To make the soil easier to work with and more closely reflect the composition of insitu soils, a quartz sand was also incorporated into the soil mixtures.

\subsubsection{Materials}

The kaolin was supplied by Sibelco UK as Powdered China Clay under the trade name Puraflo S. The montmorillonite as calcium bentonite and quartz sand (Chelford 14/25) was supplied by RS Minerals. The lime used was calcium oxide supplied by URS/Scott Wilson. Compositional analysis by X-Ray Fluorescence (XRF) is presented in Table 1 . 
The gypsum was supplied by Saint Gobain. It was supplied as crushed gypsum stone direct from the quarrying operation in Lincolnshire. This was prepared by drying at room temperature to remove surface water, then sieved to remove trace impurities of mudstone. The gypsum was passed through a jaw crusher, and then sieved again. The material passing the $425 \mu \mathrm{m}$ sieve was retained for use in the study. Confirmation that the material was the dihydrate was obtained by Thermogravimetric Analysis (TGA) and purity by Quantitative X-Ray Diffraction (QXRD). The purity of the lime was also determined by QXRD.

\subsubsection{Classification}

Material classification was undertaken in accordance with the current Highway Agency (HA) guidance on soil stabilisation for capping and subbase. The classification tests included in the programme are taken from Table 3/1 Soil Tests for Suitability and Design (HA74/07, DMRB, 2007). The soils used in the investigation are defined by the following classes (Figure 3/1 HA74/07, 2007):

- Class 7E - cohesive material improved with lime for lime stabilisation

- $\quad$ Class 9D - cohesive material stabilised by lime

Compositional analysis by XRF of the materials used in the study is presented in Table 1. 
Table 1. Chemical analysis of the kaolin, bentonite and sand by XRF.

\begin{tabular}{|c|c|c|c|c|c|c|c|c|c|c|c|c|}
\hline \multirow{2}{*}{ Oxide } & \multicolumn{12}{|c|}{ Analysis (\%) } \\
\hline & $\mathrm{SiO}_{2}$ & $\mathbf{A l}_{2} \mathbf{O}_{3}$ & $\mathrm{Fe}_{2} \mathrm{O}_{3}$ & $\mathrm{CaO}$ & MgO & $\mathbf{K}_{2} \mathbf{O}$ & $\mathrm{Na}_{2} \mathrm{O}$ & $\mathbf{P}_{2} \mathbf{O}_{3}$ & $\mathrm{TiO}_{2}$ & $\mathrm{Mn}_{3} \mathrm{O}_{4}$ & $\mathbf{V}_{2} \mathbf{O}_{5}$ & $\mathrm{Cr}_{2} \mathrm{O}_{5}$ \\
\hline Kaolin & 49.6 & 35.2 & 0.8 & 0.1 & 0.3 & 3.3 & 0.1 & - & 0.1 & - & - & - \\
\hline $\begin{array}{l}\text { Calcium } \\
\text { Bentonite }\end{array}$ & 57.7 & 18.2 & 3.1 & 1.9 & 4.2 & 3.0 & 1.7 & 0.1 & 0.4 & 0.1 & $<0.05$ & $<0.05$ \\
\hline $\begin{array}{l}\text { Quartz } \\
\text { Sand }\end{array}$ & 96.9 & 1.5 & 0.3 & - & - & 0.5 & - & - & - & - & - & - \\
\hline
\end{tabular}

Classification data and other physicochemical property data are presented in Table 2.

Table 2. Material property data.

\begin{tabular}{cccc}
\hline Property & Kaolin & Montmorillonite & Silica Sand \\
\hline Kaolinite (\%) & 68 & - & - \\
Calcium Bentonite (\%) & - & $>95$ & - \\
Muscovite Mica (\%) & 15 & - & - \\
Quartz (\%) & 1 & $<5$ & $>97$ \\
Feldspar (\%) & 5 & - & - \\
LOI & 12.0 & - & 0.5 \\
pH & 5.1 & 6.0 & - \\
Moisture (\% max) & 1.5 & 14 & - \\
LL & 52 & 103 & - \\
PL & 29 & 32 & - \\
PI & 23 & 71 & - \\
Atterberg Classification & $\mathrm{CH}$ & $\mathrm{CE}$ & \\
\hline
\end{tabular}

Note: LOI - Loss on Ignition, LL - Liquid Limit, PL - Plastic Limit, PI - Plasticity Index, $\mathrm{CH}$ - Clay of High Plasticity, CE - Clay of Extremely High Plasticity.

\subsubsection{Mixture Design}

Twelve soil mixtures were used in the study. The lime content is determined by the ICL test $+2.5 \%$ in accordance with the recommendations in HA74/07 [Highways Agency., 2007]. The amount of lime required (ICL) was determined in accordance with the procedure set out in BS 1924-2 [BSI, 1990]. The results of which are presented in Table 3 and are rounded to the nearest $0.5 \%$. 
10 Road Materials and Pavements Design. Volume X - No X/2010

Table 3. Results of Initial Consumption of Lime testing (BS1924-2, BSI. 1990).

\begin{tabular}{cc}
\hline Clay & Initial Consumption of Lime (ICL) $+\mathbf{2 . 5}(\boldsymbol{\%})$ \\
\hline Kaolinite & 4.0 \\
Montmorillonite & 6.0 \\
\hline
\end{tabular}

The soils used in the study were comprised of the unsulfated kaolin and montmorillonite clay (K and M); sulfated clay (K5S and M5S); lime stabilised clay (K4L and M6L) and sulfated lime stabilised clay with a low, medium and high sulfated content (K4L0.5S, K4L1.5S, K4L5S, ditto montmorillonite). These are shown in along with other compositional data.

Table 4 . Composition data for the artificial soils.

\begin{tabular}{|c|c|c|c|c|c|c|c|}
\hline Mix ID & $\begin{array}{l}\text { Clay } \\
\text { Type }\end{array}$ & $\begin{array}{c}\% \\
\text { Clay }\end{array}$ & $\begin{array}{c}\% \\
\text { Sand }\end{array}$ & $\begin{array}{c}\% \\
\text { Sulfate } \\
\text { (as } \\
\left.\mathrm{SO}_{4}\right) \\
\end{array}$ & $\begin{array}{c}\% \\
\text { Binder } \\
(\mathrm{CaO})\end{array}$ & $\begin{array}{c}\mathrm{OMC}+2 * \\
(\%)\end{array}$ & $\begin{array}{l}\mathrm{MDD} * * \\
\left(\mathrm{Mg} / \mathrm{m}^{3}\right)\end{array}$ \\
\hline $\mathrm{K}$ & $\mathrm{K}$ & 60.0 & 40.0 & 0.0 & 0.0 & 17.0 & 1.87 \\
\hline K5S & $\mathrm{K}$ & 60.0 & 35.0 & 5.0 & 0.0 & 17.0 & 1.84 \\
\hline K4L & $\mathrm{K}$ & 60.0 & 36.0 & 0.0 & 4.0 & 21.5 & 1.72 \\
\hline K4L0.5S & $\mathrm{K}$ & 60.0 & 35.5 & 0.5 & 4.0 & $21.5^{\dagger}$ & $1.70^{\dagger}$ \\
\hline K4L1.5S & $\mathrm{K}$ & 60.0 & 34.5 & 1.5 & 4.0 & $21.5^{\dagger}$ & $1.70^{\dagger}$ \\
\hline K4L5S & $\mathrm{K}$ & 60.0 & 31.0 & 5.0 & 4.0 & 21.5 & 1.70 \\
\hline M & M & 60.0 & 40.0 & 0.0 & 0.0 & 18.0 & 1.72 \\
\hline M5S & M & 60.0 & 35.0 & 5.0 & 0.0 & 20.5 & 1.70 \\
\hline M6L & M & 60.0 & 36.0 & 0.0 & 6.0 & 23.5 & 1.66 \\
\hline M6L0.5S & M & 60.0 & 35.5 & 0.5 & 6.0 & $22.5^{\dagger}$ & $1.66^{\dagger}$ \\
\hline M6L1.5S & M & 60.0 & 34.5 & 1.5 & 6.0 & $22.5^{\dagger}$ & $1.66^{\dagger}$ \\
\hline M6L5S & M & 60.0 & 31.0 & 5.0 & 6.0 & 22.5 & 1.66 \\
\hline
\end{tabular}

Note: $\mathrm{K}$ - kaolin, M - montmorillonite, * - Optimum Moisture Content (OMC), MDD -

Maximum dry density $\left(\mathrm{Mg} / \mathrm{m}^{3}\right),{ }^{\dagger}$ - assumed based on results from high sulfate mix.

The soils were dry blended in a 40L rotary drum mixer. Deionised water was added to the soils $\mathrm{OMC}+2$, left to condition for 1 hour, after which the lime was added with further mixing. The soil was then left to condition in a sealed bag for $24 \pm 1 \mathrm{~h}$ at $20{ }^{\circ} \mathrm{C}$ prior to production of the test specimens. 


\subsubsection{Swell Tests}

Two swell tests were used in the study. The UK linear CBR swell test (BS19242, BSI, 1990) and the European accelerated volumetric swell test (EN13286-49, CEN. 2007). The conditions of each test are presented in Table 5 along with the pass/fail criteria associated with the relevant test. If using BS1924-2 [BSI, 1990], then a minimum average strength after immersion, as well as maximum individual and average linear swell values are defined for a soil to be considered suitable for use. Using EN13286-49 only maximum volumetric swell values are taken. The average volumetric expansion $\left(\mathrm{G}_{\mathrm{v}}\right)$ is calculated using (6):

$$
G_{v}(\%)=100 \times \frac{\left[\left(V_{1}-V_{2}\right) V_{0}\right]}{V_{0}}
$$

where: $G_{v}$ is the volumetric swell, $V_{0}$ is the initial volume, $V_{1}$ is the volume after immersion, $V_{2}$ is the volume of the confinement wrapping

Table 5. Summary of conditions used in the UK CBR Linear Swell test and the European Accelerated Volumetric Swell test.

\begin{tabular}{|c|c|c|}
\hline \multirow[t]{2}{*}{ Property/Condition } & \multicolumn{2}{|c|}{ Test } \\
\hline & BS 1924-2 & EN 13286-49 \\
\hline Particle Size (mm) & $<20$ & $<6.3$ \\
\hline $\begin{array}{l}\text { Specimen Size } \\
\quad(\mathbf{m m})\end{array}$ & CBR Mould $152 \times 127$ & $50 \times 50$ \\
\hline Compaction & Proctor $(3 \times 64$ blows/layer $)$ & $\begin{array}{c}\text { Static Compaction at } 96 \pm \\
0.5 \% 1 \text { point normal proctor } \\
\text { density }\end{array}$ \\
\hline Air Cure & 3 days at $20^{\circ} \mathrm{C}$ & $72 \pm 2$ hours at $20^{\circ} \mathrm{C}$ \\
\hline Immersion & 7 or 28 days at $20^{\circ} \mathrm{C}$ & $168 \pm 4$ hours at $40{ }^{\circ} \mathrm{C}$ \\
\hline Test & $\begin{array}{c}\text { Linear Swell }(\mathrm{mm}) \text { and CBR } \\
\text { value }(\%)\end{array}$ & Volumetric Expansion $\left(\mathrm{G}_{\mathrm{v}}\right)$ \\
\hline $\begin{array}{l}\text { Suitability Criteria } \\
\text { (average of } 3 \\
\text { specimens) }\end{array}$ & $\begin{array}{c}\text { CBR }>15 \% \text {, no individual } \\
<8 \% \\
\text { Linear swell }<5 \mathrm{~mm} \text {, no } \\
\text { individual }>10 \mathrm{~mm}\end{array}$ & $\begin{array}{c}\mathrm{G}_{\mathrm{v}}<5 \% \text { suitable, } 5 \leq 10 \\
\text { generally not suitable } * 10 \\
\% \text { not suitable }\end{array}$ \\
\hline
\end{tabular}

Key: * can still be used subject to further testing in the place of use. This means that despite the EN13286-49 deeming the soil mixture generally unsuitable, it can still be used, if when subjected to additional country specific testing, 


\subsubsection{Analytical techniques}

To investigate the microstructure of the soils subject to the two swell tests, a combination of SEM and EDX was used:

- Scanning Electron Microscopy (SEM): samples were coated with Platinum using a Polaron SC7640 sputter coater. Analysis was undertaken using a Philips FEI XL30 SEM under high vacuum at a pressure of about $3.5 \times 10-6$ mbar, using an accelerating voltage of 5 $20 \mathrm{kV}$, working distance of $10-20 \mathrm{~mm}$, and a spot size of $2-5$. The image was composed from the detection of secondary electron emissions. Micrographs were analysed using ImageJ software [Rasband, 1997 - 2012].

- $\quad$ Energy Dispersive X-ray spectroscopy (EDX): undertaken to determine the elemental composition using point analysis. This was achieved using an accelerating voltage of $20 \mathrm{kV}$, a working distance of $15 \mathrm{~mm}$ and a spot size of approximately 5. The INCA EDX software programme [Oxford Instruments, was used for data and image processing.

Samples were taken from the top $5 \mathrm{~mm}$ of the CBR moulds after they had undergone testing in accordance with the UK linear swell test procedure and from the side of the European accelerated swell test specimens using a palette knife. This material was crumbled into glass dishes. These were then freeze-dried, by first freezing at $-80^{\circ} \mathrm{C}$ overnight, then vacuum drying. This procedure halted the hydration reactions thus preserving the phase assemblage and what original fine microstructure remained (petrographic analysis is difficult to perform on low strength materials due to the cutting and polishing required to produce a surface suitable for analysis). Samples for Scanning Electron Microscopy (SEM) and Energy Dispersive X-ray spectroscopy (EDX) were reserved as is.

\section{Physical Property Testing Results}

The following section reports results of the physical property testing results of the kaolin and montmorillonite soils subject to the two swell tests; UK linear CBR swell test (BS1924-2, BSI, 1990) and the European accelerated swell test (EN13286-49, CEN, 2007). The results of linear swell and strength are reported for the 28 day test.

\subsubsection{UK linear CBR swell test}

The results of the swell testing for both clay types after 28 days immersion using BS1924-2 [BSI, 1990] are presented in Figure 3 and Figure 4. 


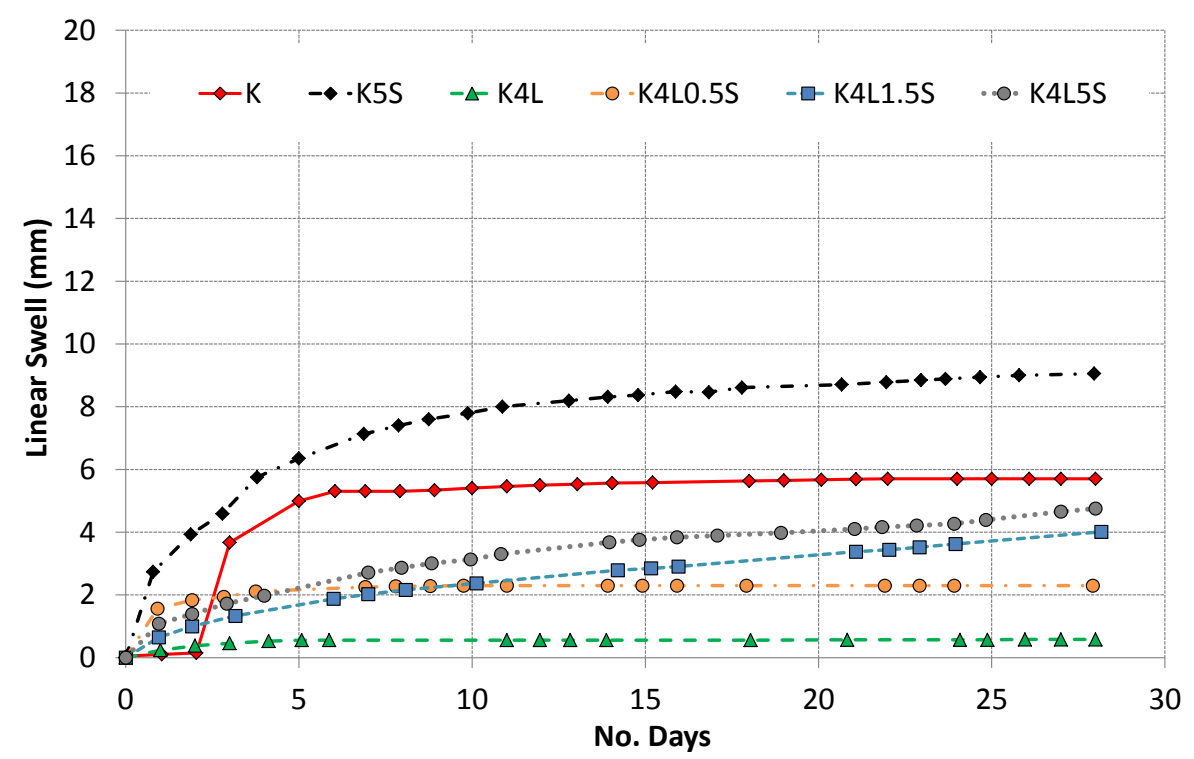

Figure 3. Linear swell results of Kaolin soils at 28 days immersion.

The unstabilised soils showed the greatest increase in linear swell. During the first three days, little swell was observed. On flooding the top of the specimen, as per the test procedure at three days immersion, the soil exhibited rapid swelling. K5S swelled significantly more than the unstabilised kaolin without sulfate from the outset of immersion. They reached a plateau at different time intervals with linear swells of 5.7 (ca. 13 days) and $9.1 \mathrm{~mm}$ (26 days) respectively (K and K5S). The stabilised clay exhibited the greatest degree of dimensional stability swelling by only $0.6 \mathrm{~mm}$ at 6 days and remained stable thereafter. The sulfated soils all exhibited swelling. K4L0.5S swelled to approximately $2.0 \mathrm{~mm}$ in 4 days immersion and again remained stable till the end of the test. Both K4L1.5S and K4L5S exhibited a proportional increase over time. Interestingly, although the overall proportion of swell was larger at the highest sulfate content (K4L5S), the rate of increase was approximately the same for both soils. At 28 days, both were continuing to swell, indicating on-going changes in composition within the cementitious matrix. 


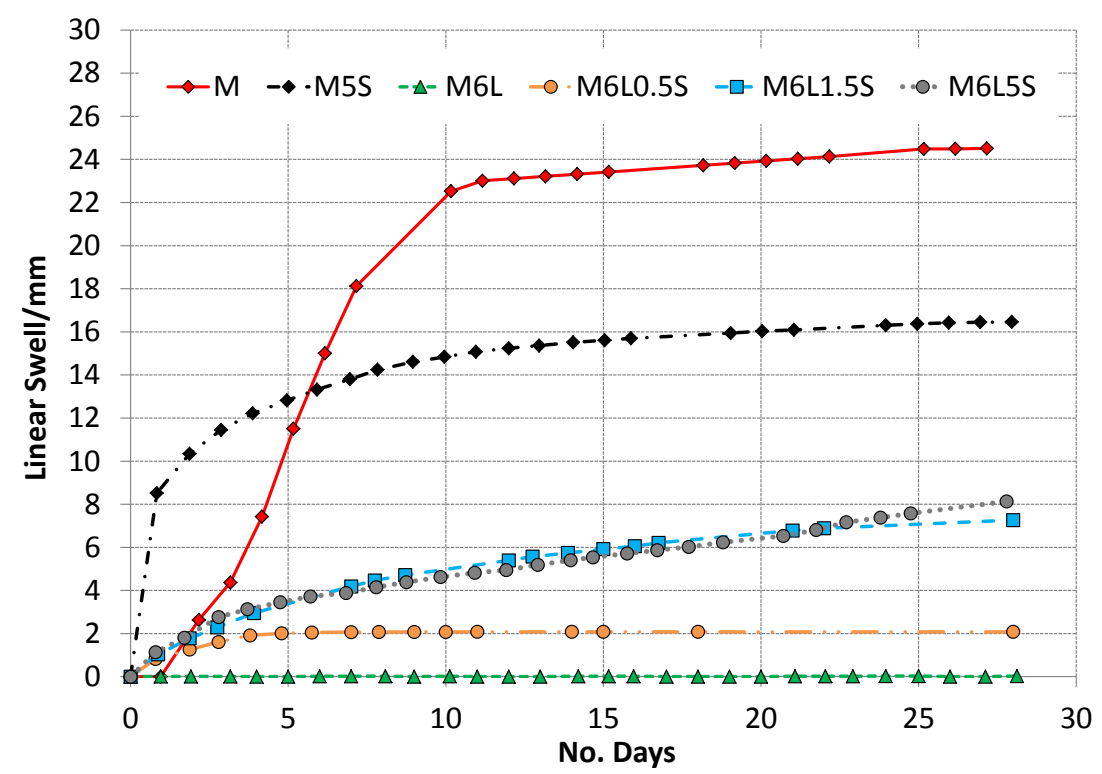

Figure 4. Linear swell results of Montmorillonite soils at 28 days immersion.

Montmorillonite soils subject to 28 day linear swell testing are shown in Figure 4. The unstabilised clays once again exhibit the greatest degree of linear swell (M $24.5 \mathrm{~mm}$ and M5S - $16.5 \mathrm{~mm}$ ). Contrary to the unstabilised kaolin clays at 28 days, it is the unsulfated clay that swelled the most. Immediately on immersion, soil mixture $M$ exhibited a relatively large swell response reaching in excess of $8 \mathrm{~mm}$ in the first $24 \mathrm{~h}$, in comparison to M5S, which took over 4 days to achieve the same degree of linear expansion. The stabilised soil M6L exhibited negligible swell (max $0.02 \mathrm{~mm}$ ) over the duration of the test. The low sulfate soil (M6L0.5S) exhibited a swell response similar to that of the equivalent kaolin (K4L0.5S). A total linear swell of $2.1 \mathrm{~mm}$ was observed, which reached a maximum after approximately 4 days immersion. The medium and high sulfate clays (M6L1.5S and M6L3S) exhibited a similar swell response, both in the rate of swell and the total dimensional increase. The rate of swell at 28 days of soil M6L3S remained constant indicating that expansive reactions were continuing, whereas the results indicate that the medium sulfate clay (M6L1.5S) was starting to plateau at around 20 days, as seen by by a flattening of the swell curve and a lower total swell at the end of the immersion (7.3 mm compared to $8.1 \mathrm{~mm}$ ).

Figure 5 shows the water contents of the soil taken from both the top and bottom of the kaolin CBR specimens after 28 days immersion (approximately 300g taken from the top $20 \mathrm{~mm}$ down from each soil face). The equivalent montmorillonites are shown in Figure 6. 


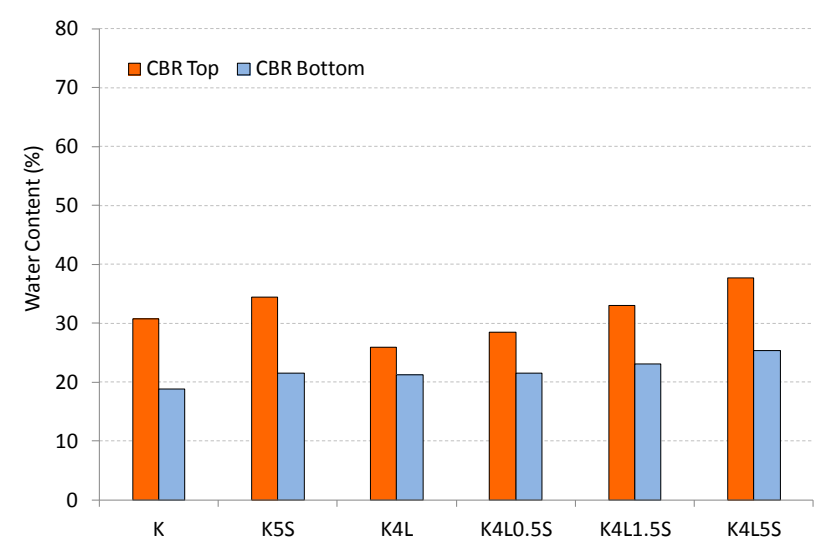

Figure 5. Water content of kaolin based soils after 28 days immersion.

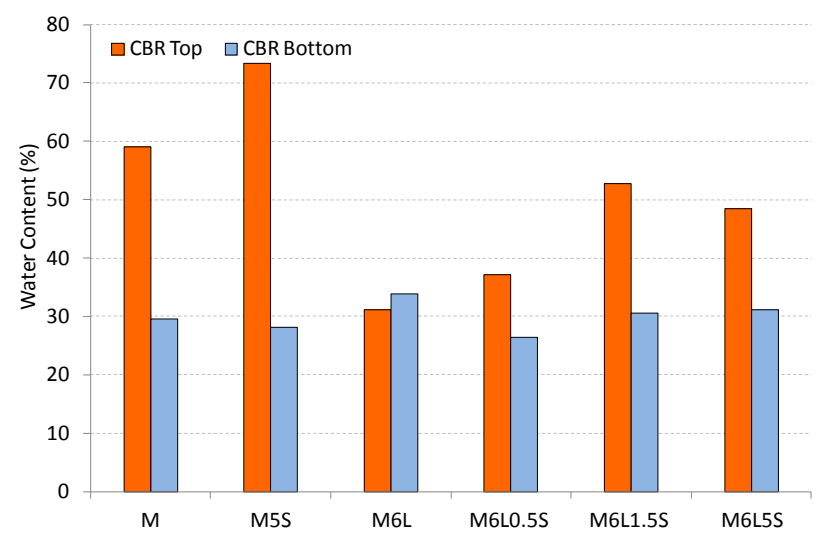

Figure 6. Water content of montmorillonite based soils after 28 days immersion.

Common to both is a proportional increase in water content of the top of the specimen with sulfate content. The bottom of the specimens remained broadly similar through the whole range of soil mixtures. Again (and as expected) the unstabilised montmorillonite soils exhibited larger water contents then the kaolin equivalents. The stabilised mixtures (K4L and M6L) had similar water contents. The difference between the top and bottom increased with sulfate content and linear swell.

Table 6 presents the soil strength of the kaolin mixtures after 28 days immersion. The unstabilised clays had CBR values of $<1 \%$ tested at both the top and bottom of the specimens. The low sulfate mixture K4L0.5S had a higher strength than the control (K4L), measuring $7 \%$ higher on the top and $35 \%$ higher on the bottom. Both the medium and high sulfate mixtures had strengths lower than the control, with K4L5S approaching that of the unstabilised soil measured on the top of the 
CBR specimen. Again the bottom faces of the sulfated kaolin soils developed a 'crust' of material that gave an artificially high strength as measured by the CBR test. The $\mathrm{pH}$ of all the specimens remained sufficiently alkaline despite the extended duration of immersion.

Table 6. Kaolin soil mixtures CBR strength at 28 days.

\begin{tabular}{ccccccc}
\hline Mix ID & K & K3S & K4L & K4L0.5S & K4L1.5S & K4L5S \\
\hline Dry Density & 1.73 & 1.70 & 1.62 & 1.64 & 1.65 & 1.61 \\
(Mg/m $\left.{ }^{3}\right)$ & $<1$ & $<1$ & 32 & 39 & 29 & 3.4 \\
CBR Top (\%) & $<1$ & $<1$ & 34 & $69 *$ & $78^{*}$ & $10^{*}$ \\
CBR Bottom (\%) & - & - & 12.81 & 12.63 & 12.87 & 12.76 \\
pH (CBR Top) & - &
\end{tabular}

Note: * - maximum strength of superficial 'crust'. At depths of $>2.5 \mathrm{~mm}$ CBR value tended to $<10 \%$.

The results of the 28 day soaked CBR testing of the montmorillonite soils are given in Table 7. The unstabilised soils again had CBR values of $<1 \%$. The control soil (M6L) achieved a relatively high strength; double that of the kaolin (K4L), 42 $\%$ higher on the top and $33 \%$ higher on the bottom than the equivalent soil tested at 7 days. All the stabilised soils exhibited higher strengths on the bottom compared to the unconfined top of the specimen. Increasing the amount of sulfate, resulted in a proportional decrease in soil strength in the order M6L > M6L0.5S > M6L1.5S > M6L3S. Again the $\mathrm{pH}$ of the soil remained alkaline after 28 days immersion.

Table 7: Montmorillonite soil mixtures CBR strength at 28 days.

\begin{tabular}{|c|c|c|c|c|c|c|}
\hline Mix ID & $\mathrm{M}$ & M5S & M6L & M6L0.5S & M6L1.5S & M6L5S \\
\hline $\begin{array}{c}\text { Dry Density } \\
\left(\mathrm{Mg} / \mathrm{m}^{3}\right)\end{array}$ & 1.51 & 1.53 & 1.40 & 1.41 & 1.42 & 1.43 \\
\hline CBR Top (\%) & $<1$ & $<1$ & 67 & 41 & 15 & 11 \\
\hline CBR Bottom (\%) & $<1$ & $<1$ & 84 & 90 & 79 & 52 \\
\hline pH (CBR Top) & - & - & 12.83 & 12.46 & 12.39 & 12.45 \\
\hline
\end{tabular}

\subsubsection{European accelerated volumetric swell test}

Figure 7 shows the plots of the average volumetric expansion $\left(G_{v}\right)$, based on testing of three identical specimens of the kaolin soils over the standard immersion period. The unstabilised clays disintegrated almost immediately. The stabilised clay swelled by $8.1 \%$, which was reached 2 to 3 days after immersion. The degree of volumetric swell exhibited by the sulfated clays was proportional to sulfate content and followed the series K4L $<$ K4L0.5S $<$ K4L1.5S $<$ K4L5S. The low sulfate soil K4L0.5S swelled to completion within the standard immersion period (168 hours/7 days). K4L1.5S appeared to be reaching a plateau at 7 days immersion, while K4L5S continued to remain volumetrically unstable and was continuing to exhibit a positive swell response. 


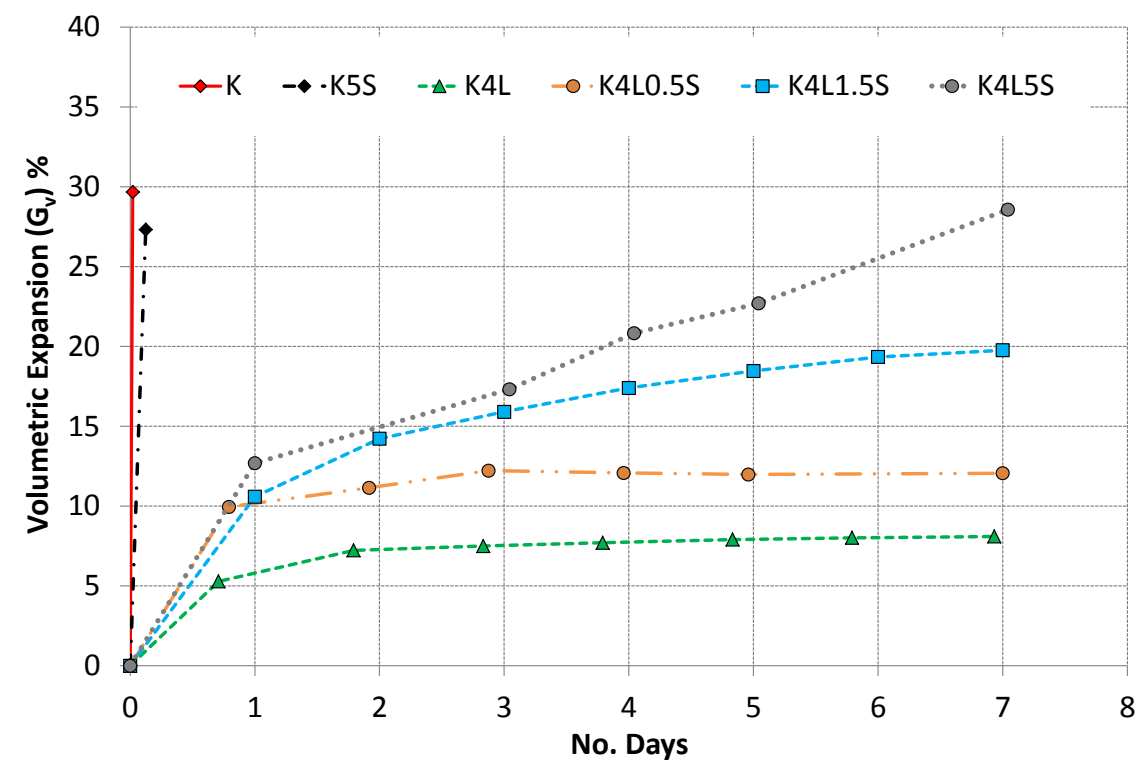

Figure 7. Swell behavior of Kaolin soils subject to the volumetric expansion $\left(G_{v}\right)$ test at 7 days (EN13286-49, CEN 2007).

The average volumetric swell response of the montmorillonite based soils is shown in Figure 8. The unstabilised clays swelled rapidly, almost reaching their maximum swell within 5 hours of immersion. Unlike their kaolin equivalents, the clay remained cohesive enough such that it could still be measured and the specimen volume calculated up to the end of the immersion period. The stabilised soil (M6L) exhibited a much reduced swell response of $1.4 \%$ within the first 5 hours, after which the clay remained volumetrically stable; until the end of the test. The swell of the sulfated stabilised clays followed the series M6L0.5S < M6L1.5S < M6L5S. After approximately 3 days immersion, the mixture M6L $0.5 \mathrm{~S}$ almost reached a plateau. During the remainder of the immersion period, the soil continued to swell but only by a relatively small amount, approximately $0.13 \%$. The medium and high sulfate soils continued to swell, although again, at a relatively reduced rate, having largely swelled to completion by approximately 5 days immersion. 


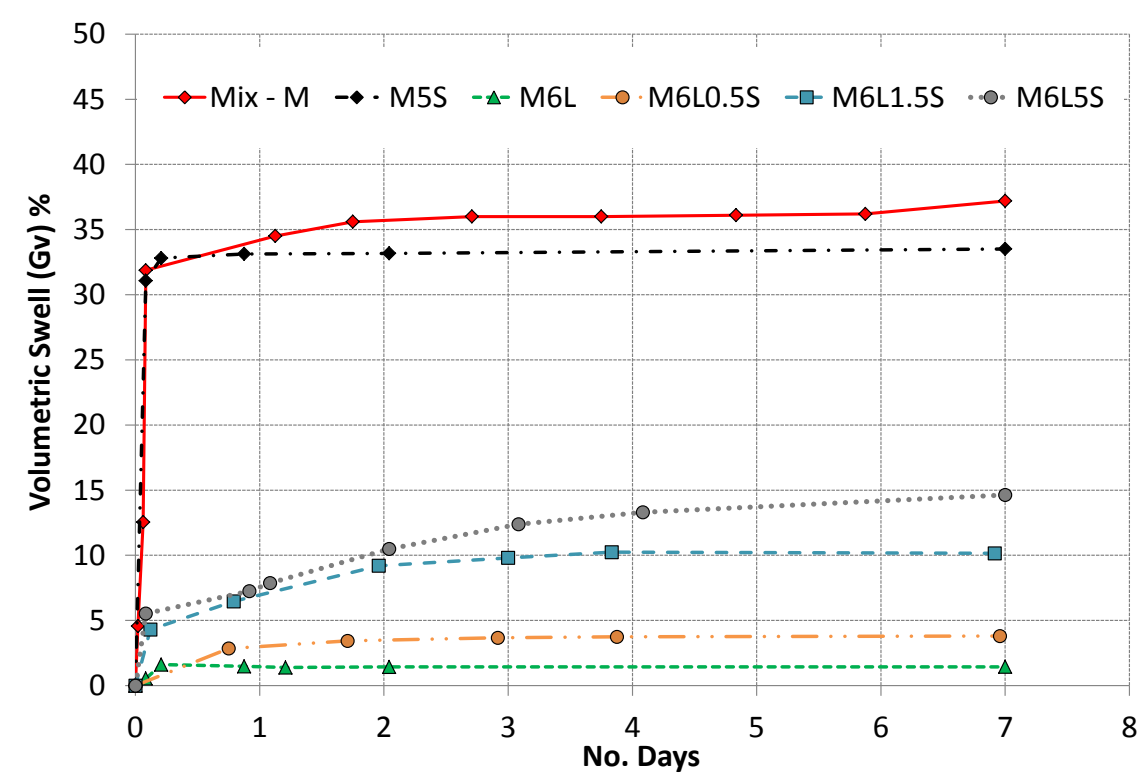

Figure 8. Swell behavior of montmorillonite soils subject to the volumetric expansion $\left(\mathrm{G}_{\mathrm{v}}\right)$ test at 7 days (EN13286-49).

\subsubsection{Discussion}

Table 8 and Table 9 show the final strength and swell values of the soils subject to the two swell tests presented in relation to the pass/fail criteria of the test. That is, the strength and swell values measured after a period of immersion as defined in the appropriate standard.

Table 8. Swell test results for kaolin soils referenced against relevant suitability criteria.

\begin{tabular}{cccccccc}
\hline Mix ID & & K & K5S & K4L & $\mathbf{0 . 5 S}$ & $\begin{array}{c}\text { K4L+ } \\
\mathbf{1 . 5 S}\end{array}$ & $\mathbf{5 S}$ \\
\hline BS1924-2 & $\begin{array}{c}\text { CBR(top) } \\
(\mathbf{\%})\end{array}$ & $<1(\mathrm{~F})$ & $<1(\mathrm{~F})$ & $32(\mathrm{P})$ & $39(\mathrm{P})$ & $29(\mathrm{P})$ & $3.4(\mathrm{~F})$ \\
& $\begin{array}{c}\text { Linear } \\
\text { Swell } \\
(\mathbf{m m})\end{array}$ & $5.7(\mathrm{~F})$ & $9.1(\mathrm{~F})$ & $0.6(\mathrm{P})$ & $2.3(\mathrm{P})$ & $4.0(\mathrm{P})$ & $4.8(\mathrm{P})$ \\
EN13286-49 & $\begin{array}{c}\mathbf{G}_{\mathbf{v}} \\
(\boldsymbol{\%})\end{array}$ & $30(\mathrm{~F})$ & $27(\mathrm{~F})$ & $8.1(\mathrm{~F} / \mathrm{P})$ & $12(\mathrm{~F})$ & $20(\mathrm{~F})$ & $29(\mathrm{~F})$ \\
\hline
\end{tabular}

Note: $\mathrm{F}$-fail, F/P - maybe suitable for use subject to further testing, $\mathrm{P}$ - pass 
Table 9. Swell test results for montmorillonite soils referenced against relevant suitability criteria.

\begin{tabular}{|c|c|c|c|c|c|c|c|}
\hline \multirow{2}{*}{ Mix ID } & & \multirow{2}{*}{$\mathbf{M}$} & \multirow{2}{*}{ M5S } & \multirow{2}{*}{ M6L } & \multicolumn{3}{|c|}{ M6L+ } \\
\hline & & & & & $0.5 \mathrm{~S}$ & $1.5 \mathrm{~S}$ & $5 S$ \\
\hline \multirow[b]{2}{*}{ BS1924-2 } & $\begin{array}{c}\text { CBR(top) } \\
(\%)\end{array}$ & $<1(\mathrm{~F})$ & $<1(\mathrm{~F})$ & $67(\mathrm{P})$ & $41(\mathrm{P})$ & $15(\mathrm{~F})$ & $11(\mathrm{~F})$ \\
\hline & $\begin{array}{c}\text { Linear } \\
\text { Swell } \\
(\mathbf{m m})\end{array}$ & $25(\mathrm{~F})$ & $16(F)$ & $<1(\mathrm{P})$ & $2.1(\mathrm{P})$ & 7.3(F) & $8.1(\mathrm{~F})$ \\
\hline $\begin{array}{c}\text { EN13286- } \\
49\end{array}$ & $\begin{array}{c}\mathbf{G}_{\mathbf{v}} \\
(\%)\end{array}$ & $37(\mathrm{~F})$ & $34(\mathrm{~F})$ & $1.4(\mathrm{P})$ & $3.8(\mathrm{P})$ & $10(\mathrm{P})$ & $15(\mathrm{P})$ \\
\hline
\end{tabular}

Note: $\mathrm{F}$-fail, F/P - maybe suitable for use subject to further testing, $\mathrm{P}$ - pass

It is possible that relatively large variances in swell of the unstabilised clays are a result of small differences in the permeability of the soils, introduced during specimen manufacture. This could result in differences in the rate of water uptake of the clay and the associated swell response, rather than fundamental differences in material behavior. The unstabilised clays for both soils exhibited characteristically high swelling and extremely low strengths after immersion. As would be expected, the montmorillonite swelled significantly more than the kaolin and is characteristic of 2:1 layer structure clays. Some variation in the ultimate linear swell values was found for the sulfated clays over their unsulfated counterparts, while the volumetric swells were similar. This could be due to variation in permeability of the top layer of the soil in the CBR moulds resulting in varying swell rates. Although given the large values, from a suitability point of view the soils would definitely be unsuitable.

The effect of lime stabilisation is apparent both in terms of a reduction in linear and volumetric swell and an increase in CBR strength. This can be attributed to the development of a cementitious matrix resulting from the pozzolanic reactions forming calcium silicate hydrates (CSH), calcium aluminosilicate hydrates (CASH) and calcium aluminate hydrates $(\mathrm{CAH})$ under the localised alkaline conditions within the soil specimens [Bell, 1996]. The increase in strength was much more pronounced for the montmorillonite soil than for the kaolin. The slower rate of strength gain of lime stabilised kaolin soils has been reported by Bell (1996), who found that ultimate strengths tended to be higher (in the region of 30 to $40 \%$ ) over the long term.

The addition of increasing amounts of sulfate to the soils, resulted in an incremental decrease in soil strength and an increase in both linear and volumetric swell. Given the relative stability of the control soil (M6L and K4L) this can be attributed to deleterious sulfate reactions within the soil matrix. Expansive sulfate reactions, in particular the formation of ettringite would account for the increase in heave as well as the loss of strength resulting from damage to the cementitious matrix [Little et al, 2010]. 
In terms of the relative severity of the tests used and their associated suitability criteria, the European accelerated volumetric swell test (EN13286-49, CEN, 2007) appears to be more onerous than the UK linear swell test (BS1924-2, BSI, 1990) on account of both the control soil (K4L) being considered not suitable for use $\left(5<\mathrm{G}_{\mathrm{v}}\right.$ $<10 \%)$ and the low sulfate soil (K4L0.5S) being considered unsuitable $\left(\mathrm{G}_{\mathrm{v}} \geq 10\right)$.

For both tests, the degree of reaction can be considered a function of the rate of swell. Considering the results of the kaolin based soils; in BS1924-2, at 28 days, both the medium $(1.5 \mathrm{~S})$ and high sulfate $(5 \mathrm{~S})$ were continuing to swell indicating on-going deleterious reactions. The low sulfate soil $(0.5 \mathrm{~S})$ had reached a plateau relatively early. In EN13286-49 (CEN, 2007), the low and medium sulfate soils had reached a plateau relatively early, while the high sulfate soil was continuing to expand, although in the montmorillonite soil, it had started to level off.

\section{Compositional Analysis}

Compositional analysis of selected soils was undertaken and the results reported in the following sections.

\subsubsection{SEM-EDX}

shows micrographs taken from the control soils (K4L and M6L) after testing to EN13286-49. In the kaolin soil (left-hand image) the typical morphology of cementitious product (Kim and Kim, 2011) can be seen on the surface of the clay particle. In the right-hand image, smectitie lamellae typical of this type can be seen as found by Yilmaz and Civelekoglu (2009). The typical acicular crystal appearance of ettringite was not found in the control specimens. 


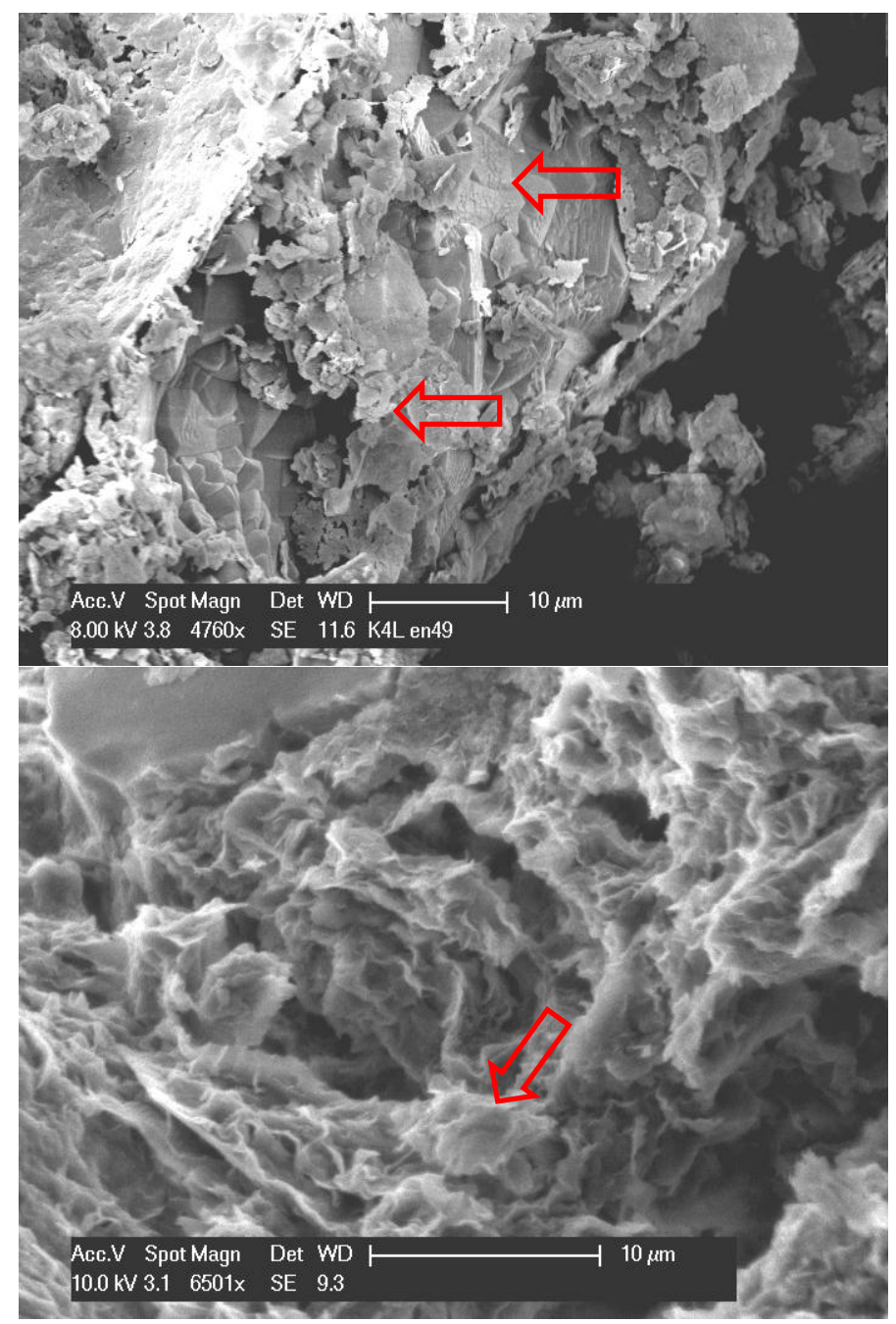

Figure 9. Control soils after European accelerated volumetric test, EN13286-49 (kaolin left, montmorillonite right).

Figure 10 shows the microstructure of K4L5S after the UK linear swell test. The spherical structures at EDX1 were identified as hydrated lime particles due to strong $\mathrm{Ca}$ and $\mathrm{O}$ emissions, as observed by Peethamparan et al, (2008). 
22 Road Materials and Pavements Design. Volume X - No X/2010

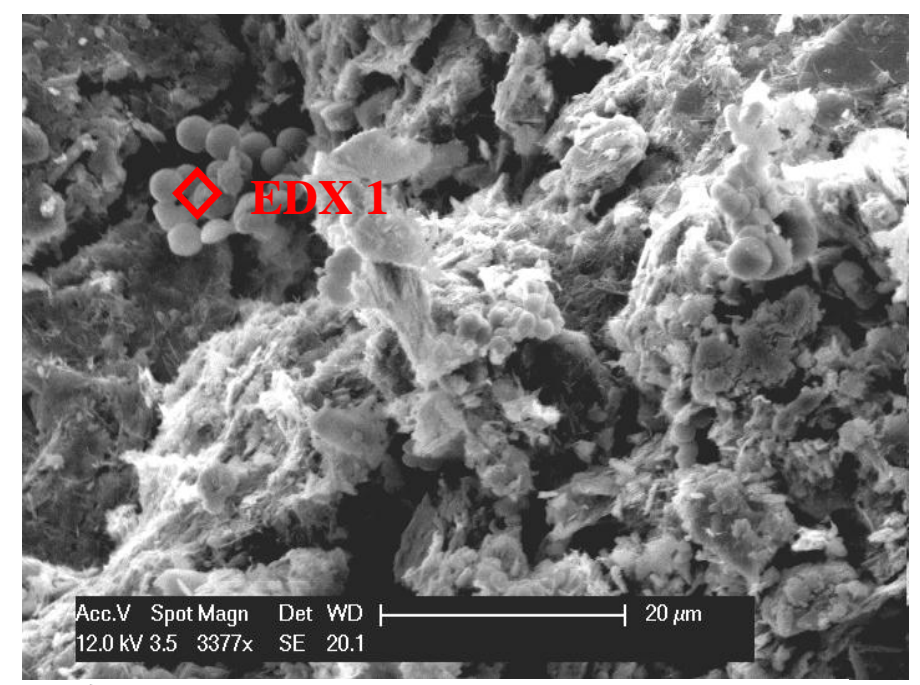

\section{EDX 1}

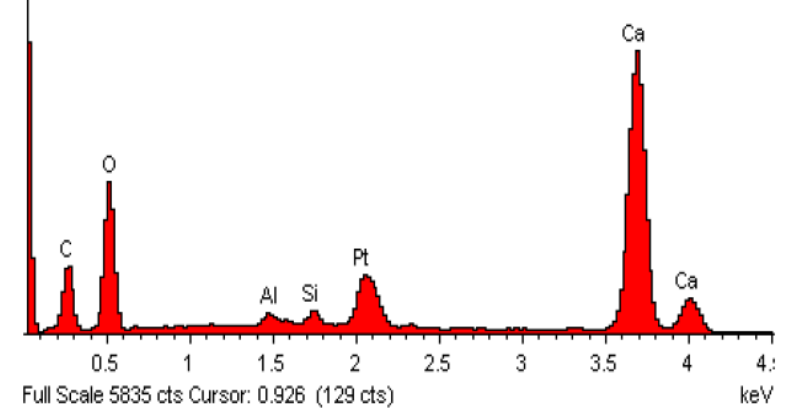

Figure 10. High sulfate kaolin soil (K4L5S) UK linear CBR swell test.

The two micrographs of Figure 11 show the characteristic needle-like morphology of ettringite. The crystals $(1)$ are small $(<3 \mu \mathrm{m}$ long and $<0.1 \mu \mathrm{m}$ wide), randomly orientated, and appear to have formed uniformly throughout the material. 


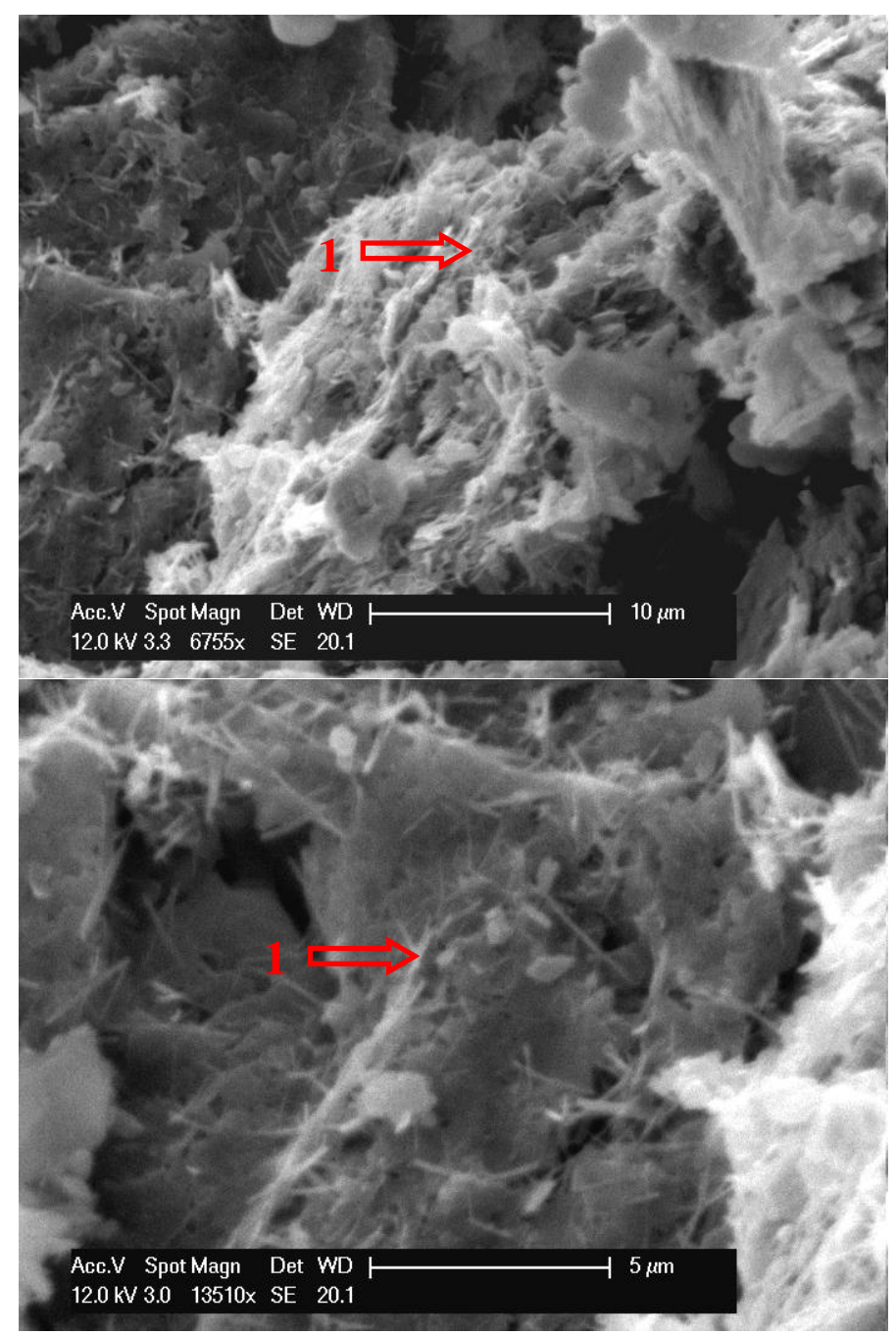

Figure 11 Ettringite found in the high sulfate kaolin soil (K4L5S) UK linear CBR swell test.

The equivalent montmorillonite soil is shown in Figure 12. No residue lime was detected. Ettringite (AFt) was found throughout the soil, confirmed by EDX (point EDX2) showing strong emissions of $\mathrm{Ca}, \mathrm{Al}, \mathrm{O}$ and $\mathrm{S}$. Adsorption of $\mathrm{Si}$ into the structure of AFt may account for the strong Si emission as well as background from the surrounding clay material. The ettringite has a different morphology to the high sulfate kaolin. The crystals are shorter but are much greater in width $(4 \mu \mathrm{m} \times 0.4$ $\mu \mathrm{m})$. These are shown at greater magnification in Figure 13. 
24 Road Materials and Pavements Design. Volume X - No X/2010

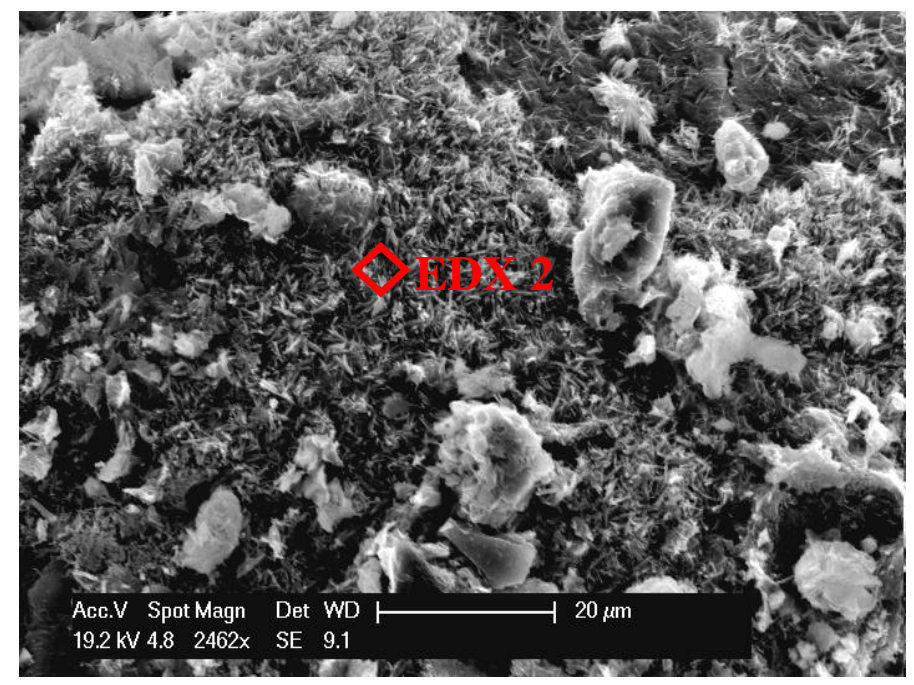

EDX 2

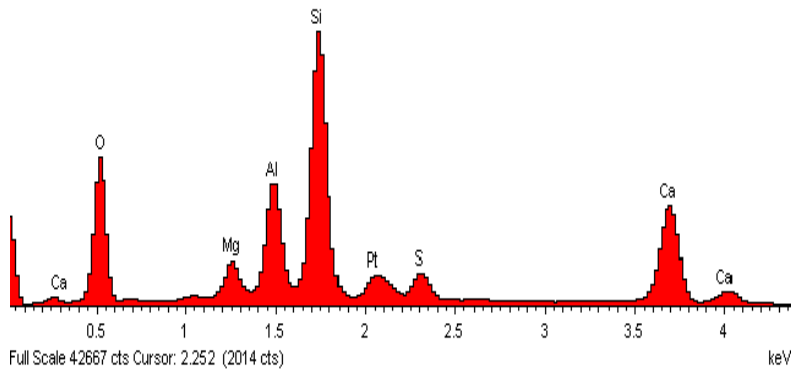

Figure 12. High sulfate Montmorillonite soil (M6L5S) UK linear CBR swell test. 


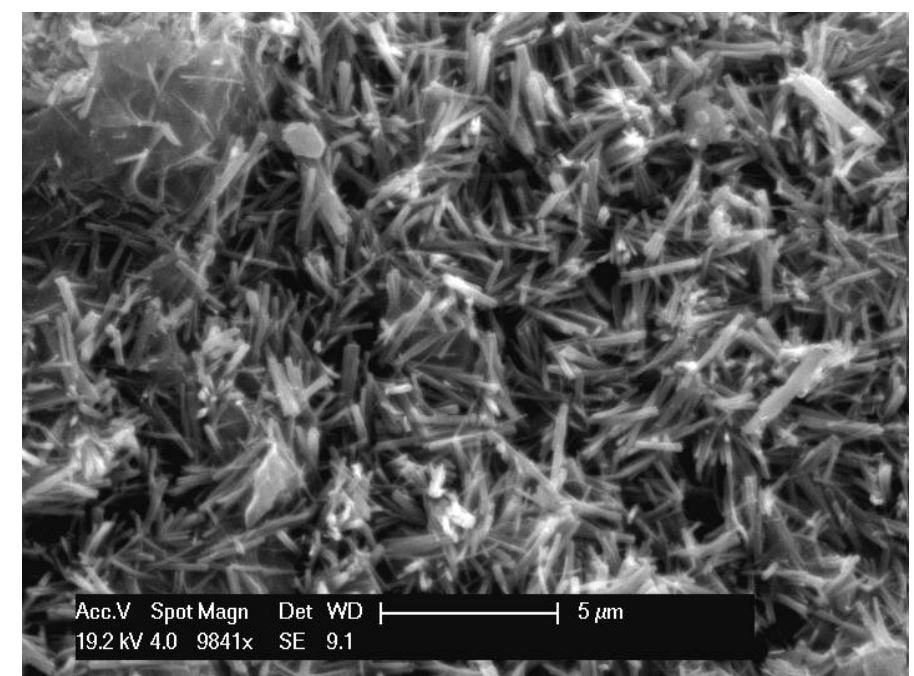

Figure 13: Ettringite crystals of the high sulfate Montmorillonite soil (M6L5S) shown under greater magnification UK linear CBR swell test 
The low sulfate soils of kaolin and montmorillonite are shown in Figure 14 and Figure 15.
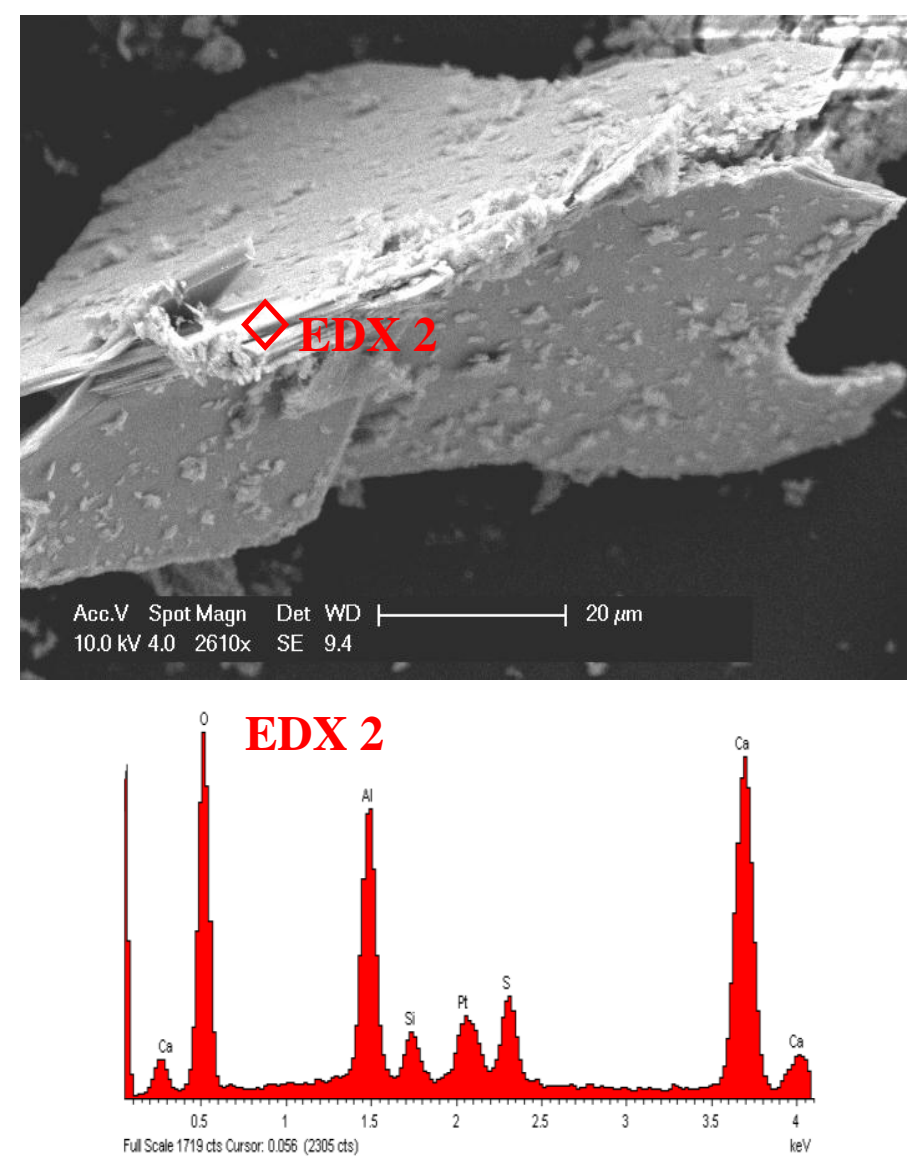

Figure 14. Low sulfate soil (K4L0.5S) UK linear CBR swell test

In the kaolin soil, the characteristic plate-like crystal morphology of monosulfate was present, confirmed by EDX analysis (EDX2). Again strong emissions of $\mathrm{Ca}, \mathrm{Al}$, $\mathrm{O}$ and $\mathrm{S}$ were recorded. These are similar to those found by Stutzman (2004) in their petrographic studies of concrete. In Figure 15, the area highlighted appears to be the remnants of what once was a void in the structure of the montmorillonite soil. Several nucleation points and radial crystal growths of AFt were found. 


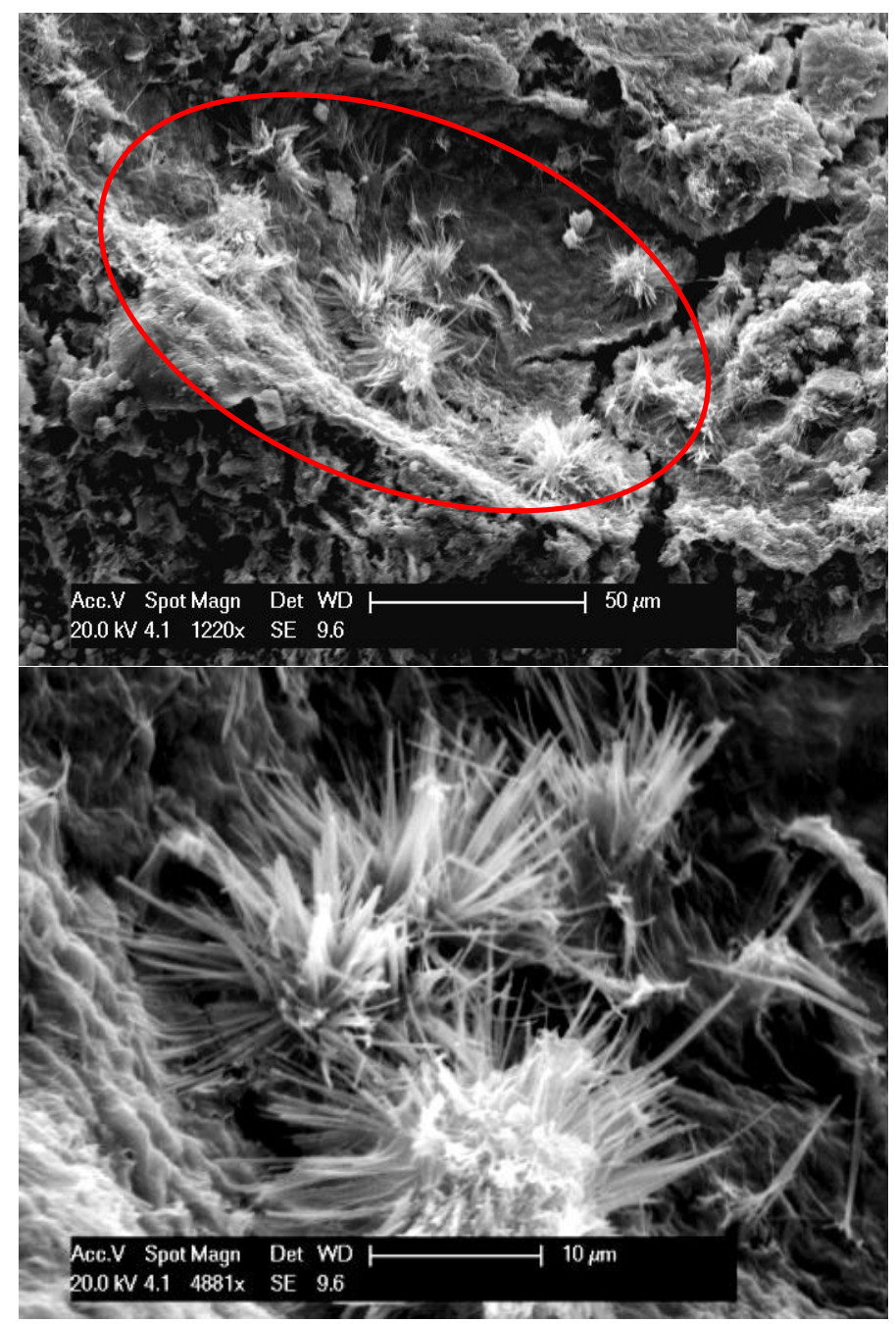

Figure 15. Low sulfate soil (M6L0.5S) UK linear CBR swell test

Figure 16 shows the high sulfate kaolin after the European accelerated swell test. Ettringite (AFt) was found throughout the soil with a morphology very similar to that found in the BS1924-2 test. 


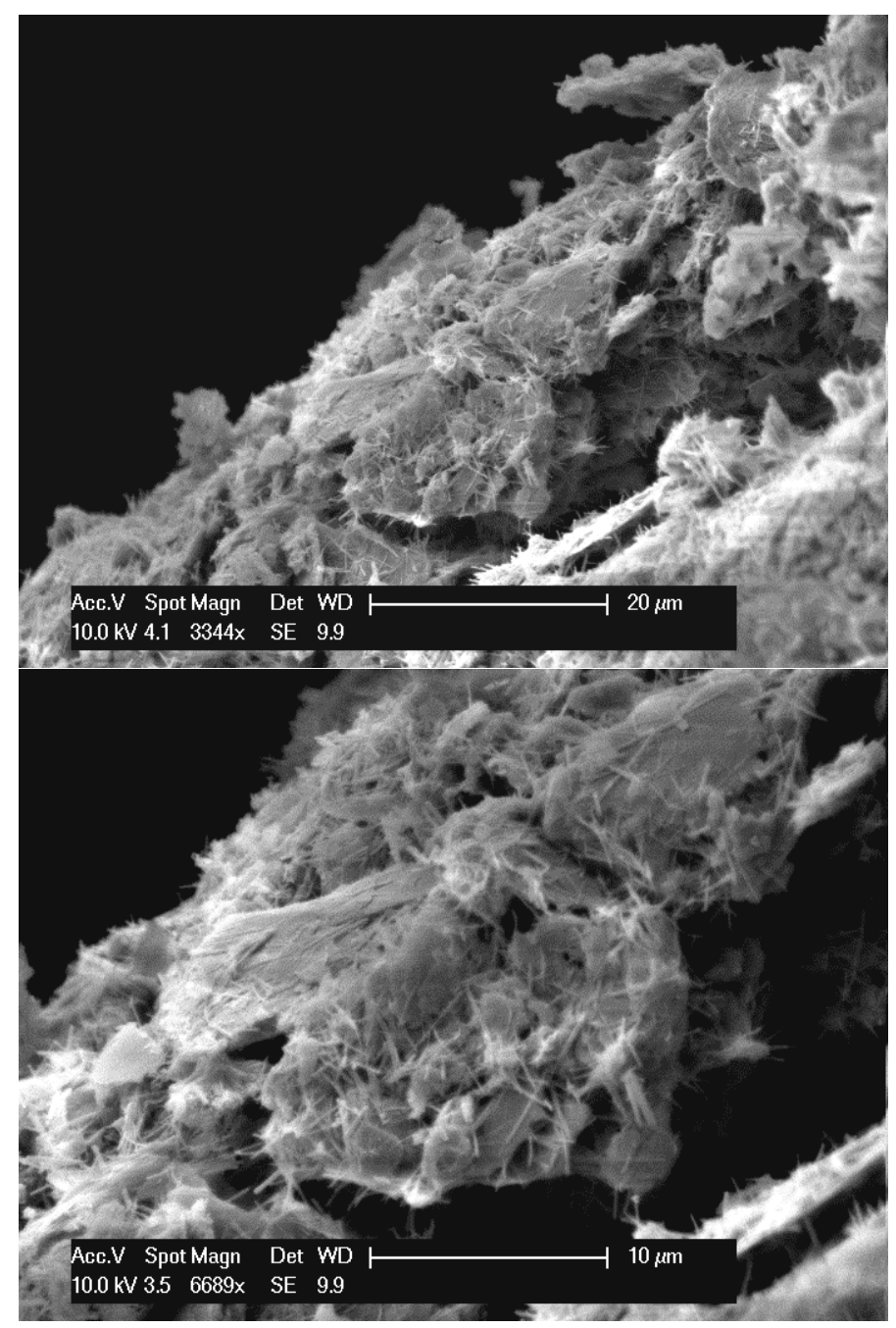

Figure 16. Acicular Ettringite crystals found in the high sulfate kaolin (K4L5S) after the European accelerated swell test, EN13286-49 (CEN, 2007)

In addition, spherical formations high in $\mathrm{Ca}$ and $\mathrm{Al}$ were found (EDX 3) as shown in Figure 17. These are much the same as those found by Tosun and Baradan (2010) in their studies of heat-cured mortars. They suggest that this is a Al-rich species that acts as a seed of what they term 'ball ettringite' that forms in the voids and narrow spaces in cement paste. 

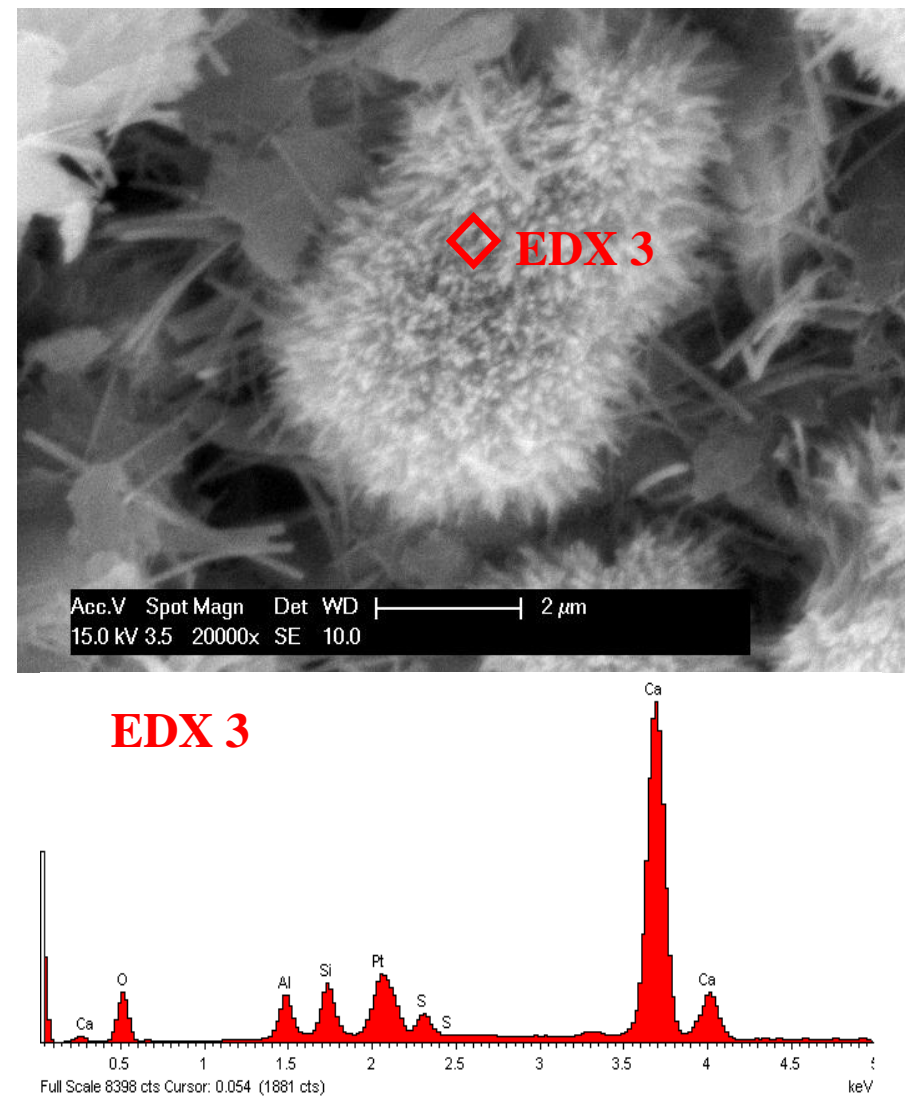

Figure 17. 'Ball ettringite' crystals found in the high sulfate kaolin (K4L5S) after the European accelerated swell test, EN13286-49 (CEN, 2007)

Figure 18 shows the equivalent montmorillonite soil. EDX analysis (EDX 4) confirms the needle-like crystals to be ettringite, due two strong elemental emissions of $\mathrm{Ca}, \mathrm{S}, \mathrm{Al}$, and $\mathrm{O}$. The bottom micrograph shows what appears to be AFt growing within a void of the microstructure (circled). The crystals in the void space are much thicker $(>1 \mu \mathrm{m})$ than those found distributed throughout the material. 
30 Road Materials and Pavements Design. Volume X - No X/2010
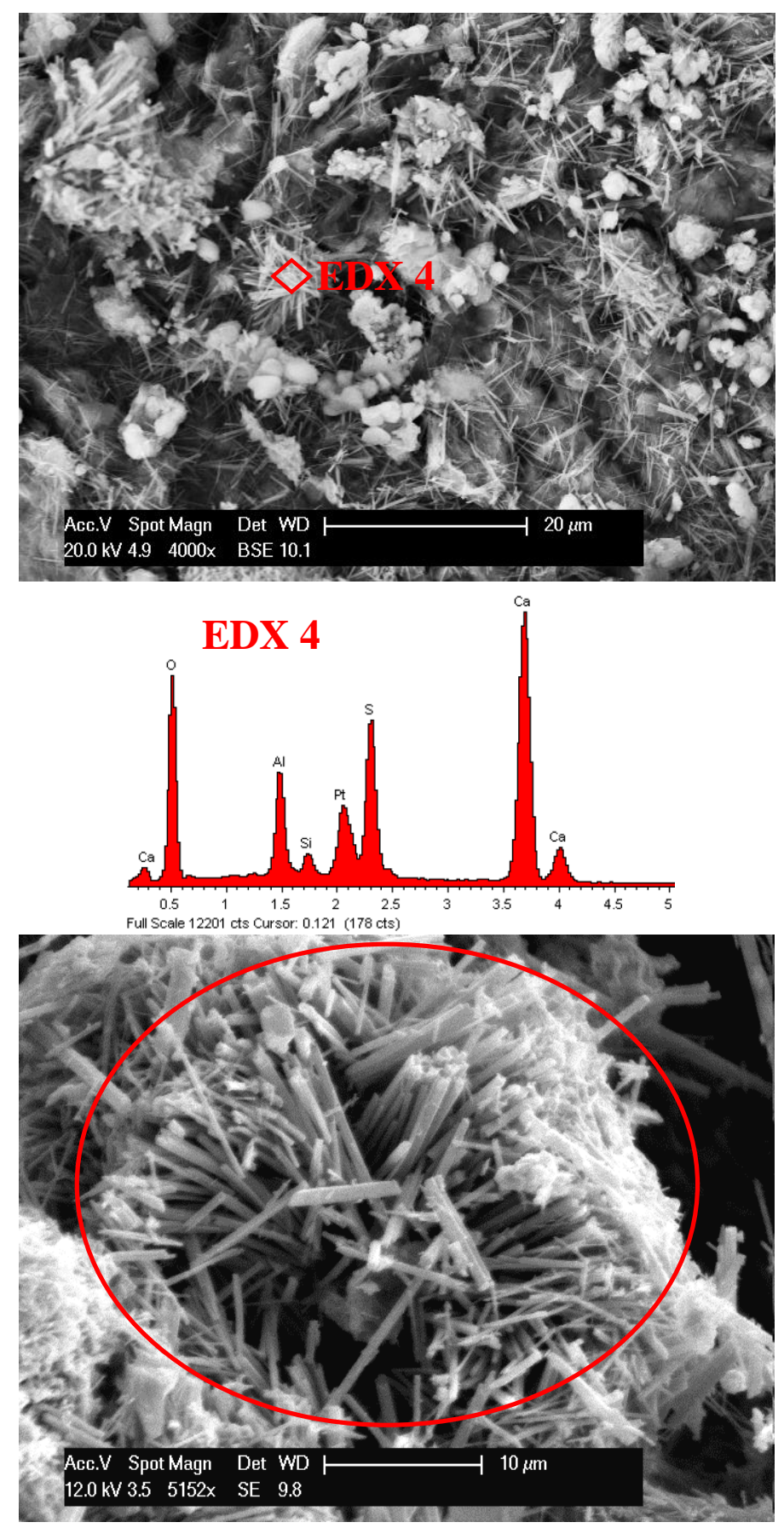

Figure 18. High sulfate montmorillonite soil (M6L5S) after the European accelerated swell test, EN13286-49 (CEN, 2007) 
Figure 19 shows the analysis of the low sulfate kaolin after the EN13286-49 test. The characteristic plate-like morphology of monosulfate was found throughout the material. The EDX analysis (EDX 5) confirms that these crystals are those of AFm due to high emissions of $\mathrm{Ca}, \mathrm{Al}, \mathrm{O}$ and $\mathrm{S}$, rather than what can be another plate-like phase - CSH [Stark and Möser, 2002]. The EDX spectrum of AFt and AFm is similar as they are comprised of the same elements. The high sulfate form, AFt was also found although compared to the other soils, this was much less abundant (Figure 20).

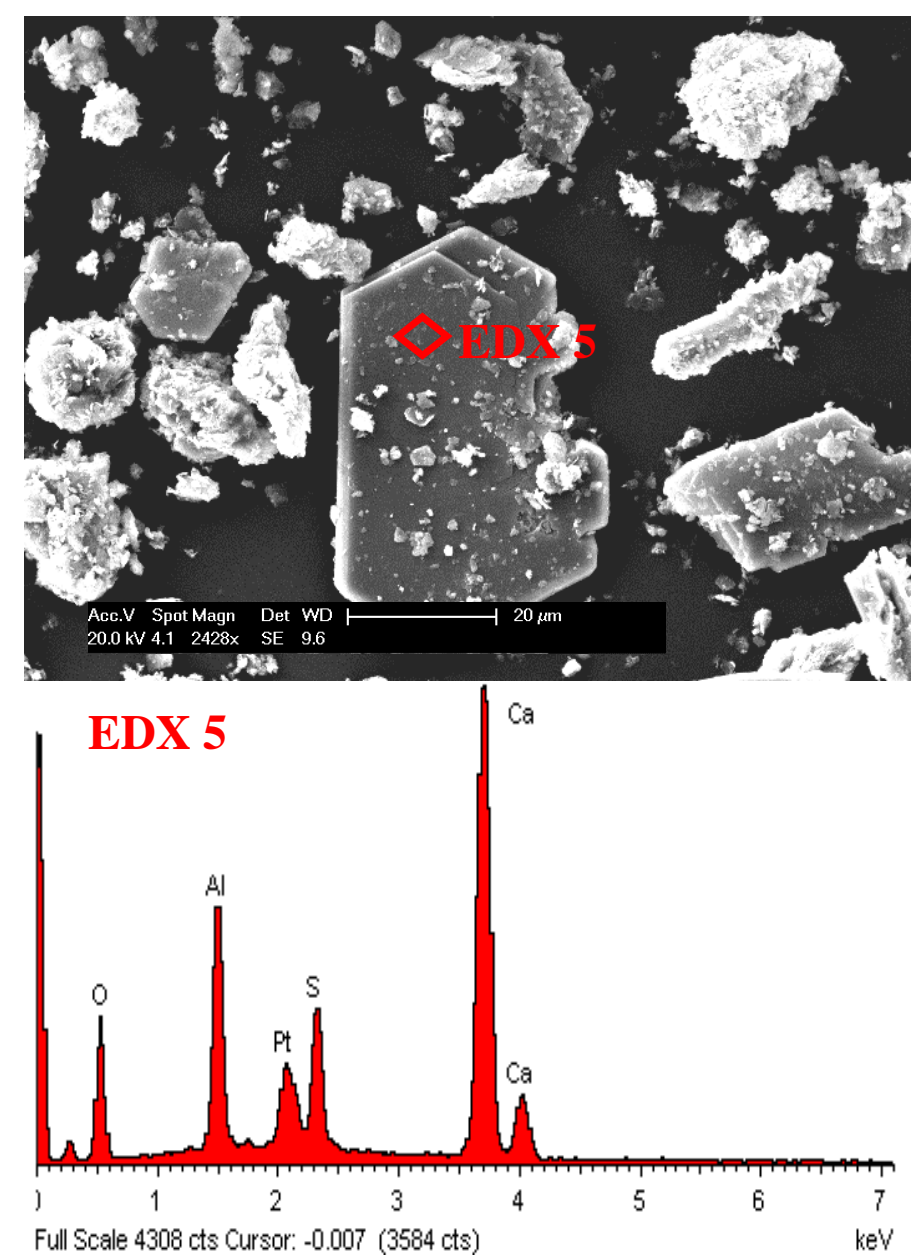

Figure 19. Monosulfate (AFm) found in the low sulfate kaolin (K4L0.5S) European accelerated swell test, EN13286-49 (CEN, 2007). 


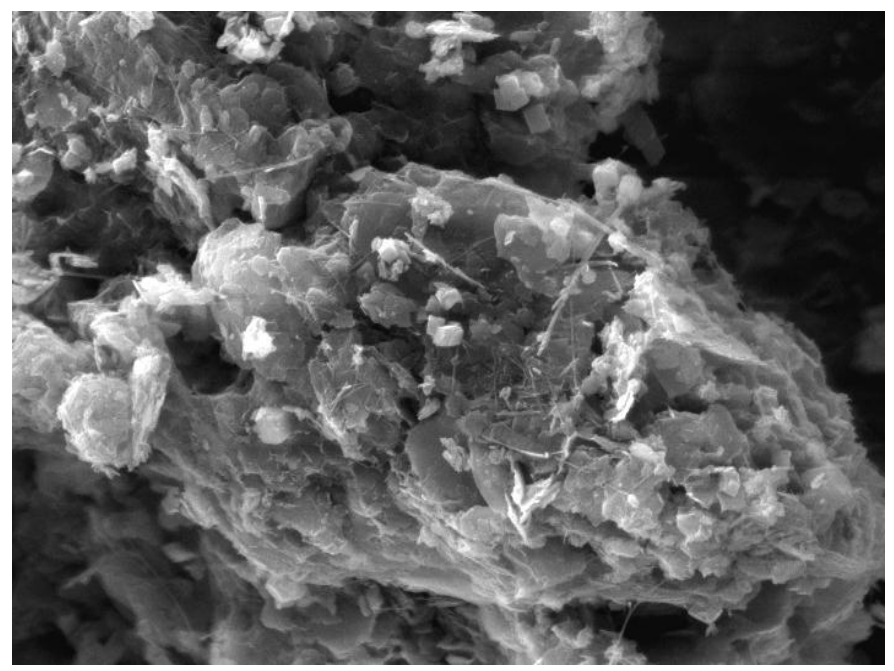

Figure 20: Ettringite found in the low sulfate kaolin (K4L0.5S) European accelerated swell test, EN13286-49 (CEN, 2007).

Figure 21 shows the equivalent montmorillonite soil. AFt was found (circled), although its occurrence was much less than the high sulfate soil. Its morphology was also similar to the kaolin having undergone the UK linear CBR swell test. The crystals were relatively long $(>15 \mu \mathrm{m})$ yet still very thin. Their width was difficult to measure but was probably $<0.5 \mu \mathrm{m})$.

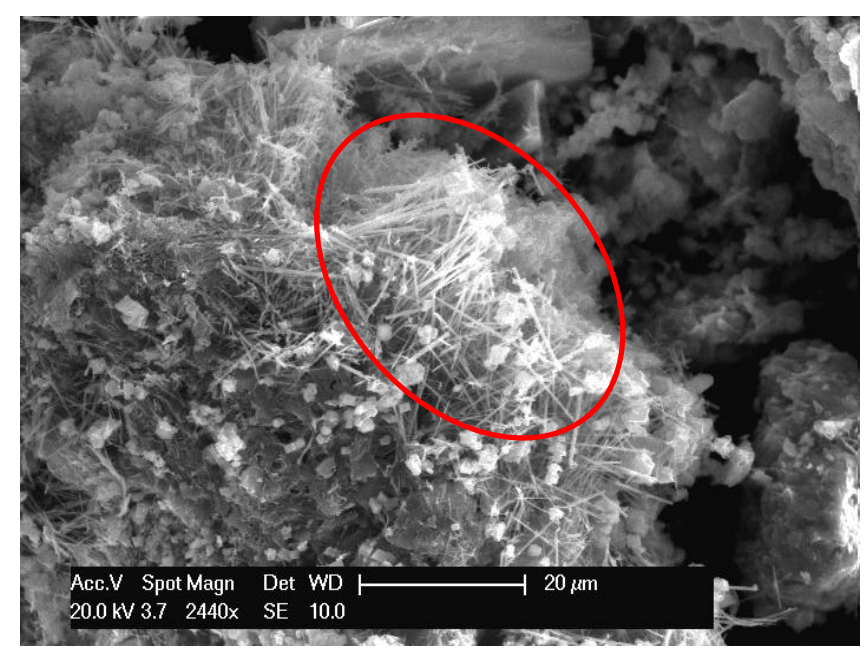

Figure 21. Ettringite found in the low sulfate montmorillonite (M6L0.5S) after the European accelerated swell test, EN13286-49. 
In EDX6 shows the emission spectrum of small cubic structures high in $\mathrm{Ca}, \mathrm{Si}$ and $\mathrm{O}$. This is possibly a calcium silicate hydrate $(\mathrm{CSH})$ cementing product similar to that found by Peethamparan et al., (2008)
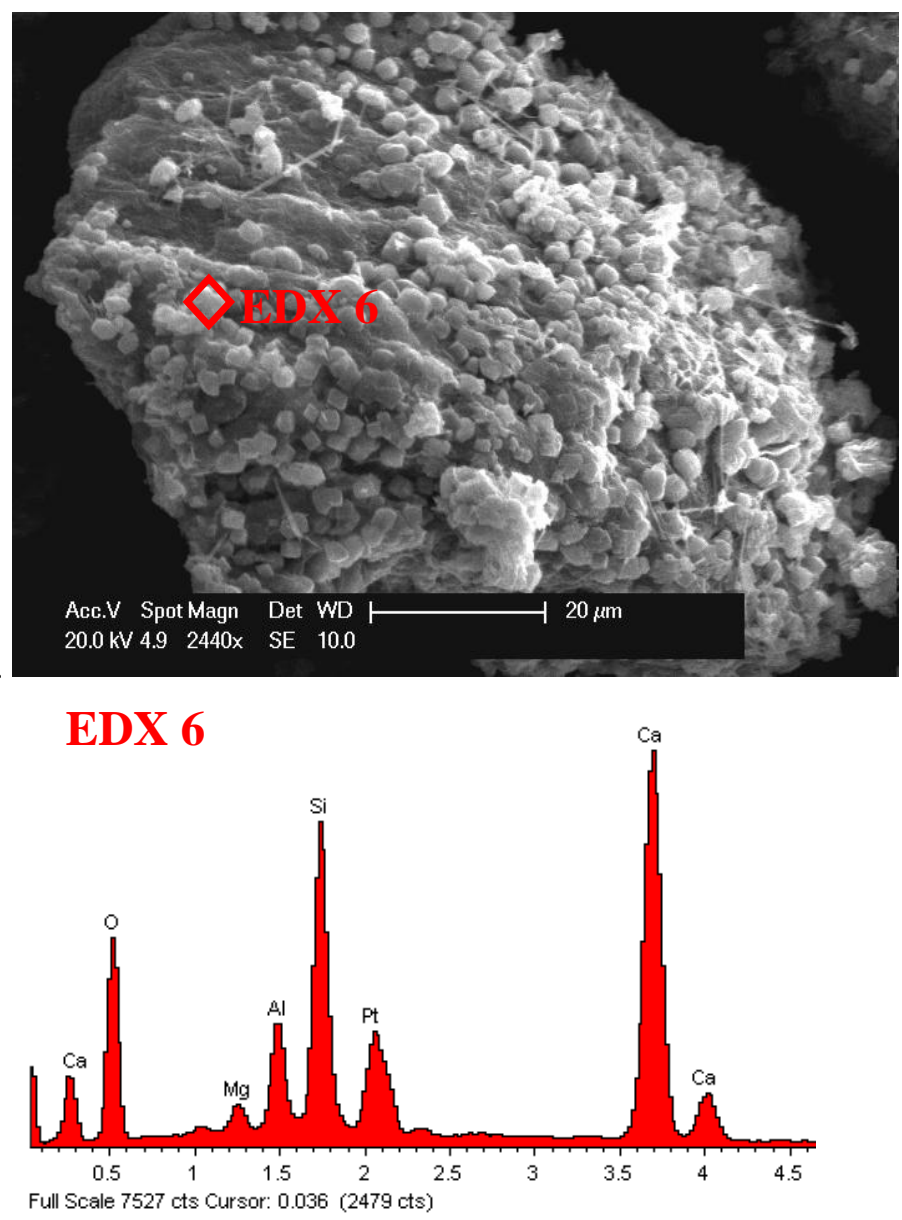

Figure 22: Cubic structures found in the low sulfate montmorillonite (M6L0.5S) after the European accelerated swell test, EN13286-49 (CEN, 2007).

\subsubsection{Discussion}

The deterioration of the soils tested in this study can be linked to the formation of ettringite and monosulfate. Analysis of the control specimens (K4L and M6L) found them to be both dimensionally stable and retained their strength after testing. Ettringite was found in the high sulfate soils of both clay types (K4L5S and M6L5S) although its morphology was dependant on the clay and the conditions of the swell 
test. Ettringite in the kaolin soil was relatively difficult to detect, due to the small size of the crystals, despite relatively large and on-going dimensional increases in the specimens at the time of analysis. It is suggested that this is evidence of topochemical colloidal AFt formation and the expansion being associated with a crystal swelling mechanism [Schwiete et al, 1966]. Some researchers have reported that kaolin clays in an alkaline environment produce a pore solution with a higher concentration of alumina compared to montmorillonite [Mitchell and Dermatas, 1990]. This coupled with a high hydroxide ion $\left(\mathrm{OH}^{-}\right)$concentration would promote such a mechanism [Min and Tang, 1993]. Conversely the AFt formed large stubby crystals throughout the montmorillonite soils suggestive of a through solution mechanism [Ogawa and Roy, 1982].

The low sulfate soil of the kaolin formed monosulfate (AFm) and smaller amounts of AFt. It is suggested that the lower concentration of gypsum, coupled with the high alumina concentration in the pore solution, resulted in conditions that were more thermodynamically favourable to the formation of monosulfate, which is known to form in what is termed a low sulfate environment [Mitchell and Dermatas, 1990]. This was surprising as monosulfate is thought only to be metastable at room temperature and very susceptible to drying [Mitchell and Dermatas, 1990; Damidot and Glasser, 1992]. The montmorillonite (M6L0.5S, Figure 15) showed evidence of AFt formation in the void structure of the soil, further supporting a through-solution mechanism of formation.

In the European accelerated swell test the high sulfate kaolin soil exhibited significant on-going volumetric swell at the time of analysis (Figure 7). SEM-EDX analysis again showed evidence of colloidal AFt formation, but also Al-rich structures (Figure 16) that act as seed points for later formation of the more typical needle-like AFt crystals [Tosun and Baradan, 2010]. This 'early-age' ettringite is consistent with the recorded on-going increase in volumetric swell. In the equivalent montmorillonite soil, the long and thin crystals of $\mathrm{AFt}$ associated with a topochemical formation mechanism, as well as short, thicker crystals in void structures (through-solution) were found. It is possible that the higher immersion temperature increased the solubility of candidate ions and localised variations in conditions allowed the co-formation of ettringite by both mechanisms. The low sulfate kaolin soil (K4L0.5S) formed comparatively more AFm than the same soil tested under BS1924-2. After some initial expansion on immersion, it remained dimensionally stable. This supports the accepted theory that monosulfate does not contribute to expansion [Mitchell and Dermatas, 1990]. The low sulfate montmorillonite (M6L0.5S), yielded AFt only (see Figure 21). Its morphology was similar to that formed in the UK linear CBR swell test of the same soil (Figure 15).

\section{Conclusions}

Based on the results of this research the following conclusions can be drawn: 
- Lime stabilised cohesive soils with increasing amounts of sulfate, exhibit a proportional degree of dimensional instability and loss of strength, when subject to swell testing. This can be attributed to the formation of the hydrous calciumsulfoaluminate species ettringite $(\mathrm{AFt})$;

- $\quad$ For formation of monosulfate (AFm) was limited to those soils that were low in sulfate $(0.5 \%)$. Aside from the controls, these also exhibited the lowest degree of expansion;

- Relating the physical property results to suitability criteria of the two swell tests, the European accelerated swell test is considered more onerous than the UK linear CBR swell test at 28 days;

- The mechanisms of formation and expansion were not the same for each soil and were found to be affected by: clay type; sulfate content and swell test conditions;

- In the soils tested evidence was found to support both swelling mechanisms (topochemical formation/crystal swelling; and throughsolution/crystal growth); and

- Ettringite can exhibit a range of morphologies dependant on the physico-chemical environment in which it forms. 


\section{References:}

- Basista, M and Weglewski, W (2009). "Chemically assisted damage of concrete: A model of expansion under external sulfate attack". International Journal of Damage Mechanics, Vol.18, pp155 - 175.

- Bell F.G. "Lime stabilization of clay minerals and soils". Engineering Geology, Vol. 42, pp. 223 - 237, 1996.

- British Standards Institute (BSI). "Stabilized materials for civil engineering purposes - Part 2: Methods of test for cement-stabilized and lime-stabilized materials", BS1924-2, 1990.

- $\quad$ Britpave (2010 - 2011). Case Study 1 - 10. http://www.britpave.org.uk/SoilStabCaseStudies.ink. www.britpave.org.uk.

- $\quad$ Brown, P.W. and Taylor, H.F.W., "The role of ettringite in external sulphate attack". Materials Science of Concrete Special Volume: Sulphate Attack Mechanisms, The American Ceramic Society, Westerville, OH, pp.73 - 98, 1999.

- Cerato A.B., Miller, G.E., and Elwood-Madden, M., (2011). "Calcium-based stabilizer induced heave in Oklahoma sulfate-bearing soils". Oklahoma Department of Transportation, Final Report - FHWA-OK-11-03. ODOT SPR item number 2210.

- Chen, S.S. and Mehta, P.K., (1982). "Zeta potential and surface area measurements on ettringite". Cement and Concrete Research. Vol.12, No.2, pp. $257-259$.

- Cohen, M.D., (1983). "Theories of expansion in sulfoaluminate - type expansive cements: Schools of thought", Cement and Concrete Research, Vol. 13, pp. $809-818,1983$.

- Damidot, D, and Glasser, F.D., (1992). "Thermodynamic investigation of the $\mathrm{CaO}-\mathrm{Al}_{2} \mathrm{O}_{3}-\mathrm{CaSO}_{4}-\mathrm{H}_{2} \mathrm{O}$ system at $25^{\circ} \mathrm{C}$ and $85^{\circ} \mathrm{C}$ '. Cement and Concrete Research, Vol. 22, pp. $1179-1191$.

- Eades, J.L., and Grim, R.E., (1966). "A quick test to determine lime requirements for lime stabilisation". Transportation research Board, Highway Research Record, No. 139, pp. $61-72$.

- European Committee for Standardization, (2007). "Unbound and hydraulically bound mixtures - Part 49: Accelerated swelling test for soil treated by lime and/or hydraulic binder", EN13286-49, 2004.

- Highways Agency., (2007). Design Manual for Roads and Bridges: Volume 4. Geotechnics and Drainage. HA74/07, Treatment of Fill and Capping Materials Using Either Lime or Cement or Both.

- Highways Agency. (2007). Manual of Contract Documents for Highway Works. Volume 1 - Specification for Highway Works, UK. 
- Hunter, D., (1988). "Lime-Induced heave in sulfate bearing clay soils". Journal of Geotechnical Engineering, Volume 114, Issue 2, pp. 150 - 167.

- Ish-Shalom, M., and Bentur, A., (1974). "Properties of Type-K cement of pure components I: yydration of unrestrained pastes of pure components: results", Cement and Concrete Research, Vol.4, pp.519-532.

- Kalousek, G.L. and Benton, E.J., (1970). "Mechanism of Seawater Attack on Cement Pastes”, ACI Journal, Vol. 67, No. 9, pp.187-192.

- Kirchheim A.P., Ferna`ndez-Altable, V., Monteiro, P. J. M., Molin, D. C. C., and Casanova, I., (2009). "Analysis of cubic and orthorhombic C3A hydration in presence of gypsum and lime". Journal of Materials Science, Vol.44, pp.2038-2045.

- Kim, T. and Kim, Y., (2011). Unconfined compressive strength and microstructural properties of cemented sand and gravel materials. Scientific Research and Essays, Vol. 6, No.4, pp. 933 - 948.

- Kota, P.B.V.S., Hazlett, D., and Perrin, L., (1996). "Sulfate-bearing soils: Problems with calcium based stabilizers. Journal of the Transportation Research Board, Vol. 1546, pp. 62 - 69.

- Little D.N., Nair, S., and Herbert, B., (2010). “Addressing Sulfate-Induced Heave in Lime Treated Soils". Journal of Geotechnical and Geoenvironmental Engineering, Vol.136, No. 1, pp. 110 - 118.

- $\quad$ Locat, J., Bérubé, M., and Choquette., M., (1990). "Laboratory investigations on the lime stabilization of sensitive clays: shear strength development." Journal of Canadian Geotechnics. Vol.27, pp. 294-304.

- McNally, G.H., (1998). Soil and Rock Construction Materials. Spon Press, ISBN: 978-0-419-21420-5.

- Mehta, P.K., (1973). "Mechanism of expansion associated with ettringite formation". Cement and Concrete Research, Vol.3, pp1-6.

- Mehta, P.K., (1976). "Scanning electron microscope studies of ettringite formation”. Cement and Concrete Research, Vol. 6, Part 2, pp169 - 192.

- $\quad$ Mehta, P.K and Hu, F.J., (1978). "Further Evidence for Expansion of Ettringite by Water Adsorption". Journal of the American Ceramic Society, Vol.61, Issue 3-4, pp179- 181.

- Mehta, P.K. and Wang, S., (1982). "Expansion of ettringite by water absorption", Cement and Concrete Research, Vol.12, pp.121-122.

- Min, D. and Tang, M., (1994). "Formation and expansion of ettringite crystals". Cement and Concrete Research, Vol. 24, Part 1, pp119-126.

- Mitchell, J.K, Dermatas, D., (1990). "Clay soil heave caused by lime-sulfate reactions". Innovations and Uses for Lime. ASTM STP 1135. ASTM, Philadelphia, pp. 41- 64. 
- Mohamed, A.M.O., (2000). "The role of clay minerals in marly soils on its stability”. Engineering Geology, Vol. 57, pp. 193 - 203.

- Nakamura, T., Sudoh, T., and Akaiwa., S., (1960). "Mineralogical composition of expansive cement clinker rich in $\mathrm{SiO}_{2}$ and its expansibility". Proc., $5^{\text {th }}$ International Symp. On Chem. Of Cem. Tokyo, Vol.4, pp351.

- Odler, I. and Gasser, M., (1988). "Mechanism of sulphate expansion in hydrated Portland cement", Journal of the American Ceramic Society, Vol. 71, pp.10151020.

- Ogawa, K. and Roy, D.M., (1982). " $\mathrm{C}_{4} \mathrm{~A}_{3} \mathrm{~S}$ hydration, ettringite formation, and its expansion mechanism: II. Microstructural observation of expansion". Cement and Concrete Research, Vol.12, Part 1, pp101-109.

- Peethamparan, S., Olek, J., and Lovell, J., (2008), "Influence of chemical and physical characteristics of cement kiln dusts (CKDs) on their hydration behaviour and potential suitability for soil stabilization." Cement and Concrete Research, Vol.38, pp. 803-815, 2008.

- Perrin, L., (1992). "Expansion of lime-treated clays containing sulphates". Proceedings of the Seventh International Conference on Expansive Soils, ASCE Expansive Soils Research Council, New York, Vol.1, pp. 409-414.

- Ping, X. and Beaudoin, J.J., (1992). "Mechanism of sulfate expansion I. Thermodynamic principal of crystallisation pressure." Cement and Concrete Research, Vol.22, pp.631-640.

- Puppala, A., Intharasombat, N., and Vempati, R.., (2005). "Experimental Studies on Ettringite-Induced Heaving in Soils". Journal of Geotechnical and Geoenvironmental Engineering, Vol. 131, No. 3, pp. 325 - 337.

- Rasband, W.S., (1997 - 2012). ImageJ, U. S. National Institutes of Health, Bethesda, Maryland, USA, http://imagej.nih.gov/ij/.

- Rollings, R. and Burkes, J.P., (1999). "Sulfate attack on cement-stabilized sand". Journal of Geotechnical Engineering and Geoenvironmental Engineering, Vol. 125, No.5, pp. $364-372$.

- Schwiete, H.E., Ludwig, U., and Jager, P., (1966). "Investigations in the System $3 \mathrm{CaO} . \mathrm{Al}_{2} \mathrm{O}_{3}-\mathrm{CaSO}_{4}-\mathrm{CaO}-\mathrm{H}_{2} \mathrm{O}$ ". Symposium on Structure of Portland Cement Paste and Concrete. Special Report 90, Highway Research Board, National Research Council, pp. $353-367$.

- Sherwood, P.T., (1962). "Effect of sulfate on cement and sulphate treated soils". Highways Research Board Bulletin. Vol. 353, pp. 98 - 107.

- $\quad$ Snedker, E.A and Temporal, J., (1990). "M40 Motorway Banbury IV Contract Lime Stabilisation". Highways and Transportation, December, pp. $142-158$.

- Soroka, I., (1979). "Portland cement paste and concrete". Chemical Publishing Company, New York. 
- Stark, J. and Möser, B., (2002). "Nano and microstructure of Portland cement paste". Frost Resistance of Concrete. Proc. Of the Int. RILEM Workshop, RILEM, France.

- Stutzman, P.E., (2006). "Petrographic methods of examining hardened concrete: a petrographic manual" Virginia Transportation Research Council (VTRC), Report VTRC-92-R14, Chapter 14.

- West, G., and Carder, D.R., (1997). "Review of lime piles and lime-stabilised soil columns." TRL Report 305, Transport Research Laboratory, The Highways Agency, Berkshire, UK.

- Yilmaz, I. and Civelekoglu, B., (2009). "Gypsum: an additive for stabilization of swelling clay soils.” Applied Clay Science. Vol. 44, pp. 166 - 172. 